\title{
Analysis of Historical Monthly, Seasonal and Annual Rainfall Variability (1990-2014) in Machakos Sub County, Kenya
}

\author{
Christopher M. Indiatsy \\ School of Environment and Earth Sciences (Geography Department.), Maseno University Kenya \\ Received 01 Nov 2017, Accepted 01 Jan 2018, Available online 10 Jan 2018, Vol.6 (Jan/Feb 2018 issue)
}

\begin{abstract}
Varying climatic conditions with increased uncertainty mainly in rainfall and temperature are salient features in marginal areas globally, adversely affecting farming activities particularly in Africa. Kenya experiences variations of annual rainfall with considerable uncertainty. These variations ranging from below 500mm to above 2000mm annually, cause droughts and floods respectively, affecting farming activities and yields. This study attempts to analyze historical monthly, seasonal and annual rainfall variability in Machakos sub County between 1990 - 2014. Studies on analysis of rainfall variability covered in Machakos have dwelt on broad and expansive areas of Eastern and South Eastern Kenya including Machakos, Kitui and Makueni Counties. Broad studies give generalized information which may not give true and adequate results for some specific areas. This has prompted the need to focus on a smaller area. This study focused on Machakos sub County, a semi arid area, East of Central Kenya highlands. Existing studies in the mentioned areas, mainly cover the period between 1930 - 1990. After this period, very scarce information exists. The main objective of the study was to establish the historical monthly, seasonal and annual rainfall variability in Machakos sub county between 1990 - 2014. Publications from Meteorological Department Nairobi and sub county Agricultural offices, provided rainfall data. Using SPSS, quantitative data was analyzed using descriptive statistics such as Means, Standard deviation and percentages. Inferential statistics using Pearson's Correlation technique was used to determine relationships between variables. Coefficient of variability, Relative variability and Precipitation Concentration index measured Rainfall Variability. The study established that monthly, seasonal and annual rainfall distribution in Machakos sub County was highly variable, erratic and unpredictable over the 25 years with a CV of $24 \%$ and a PCl of 10 . There is high temporal rainfall variability (CV of $24 \%$ and $\mathrm{PCl}$ of 10 ) in the sub County. Disseminating information on rainfall forecasts, rainwater harvesting for irrigation, proper cattle stocking, a forestation and reforestation programs were highly recommended.
\end{abstract}

Keywords: Rainfall variability, drought intensity, anomaly, relative variability, coefficient of variability, precipitation concentration index and erratic rainfall.

\section{Introduction}

Rain is the most important element determining climate and the world's climate is categorized based on rainfall and temperature. Variability of rainfall is a global problem disrupting farming activities in most parts of the world. The Main objective of this study was to establish the historical monthly, seasonal and annual rainfall variability in Machakos sub County. The study area was limited to Machakos sub County which is a semi arid area in Eastern Kenya. This study commences with the Background to the Problem, the statement of the problem, research objective, literature review, Methodology and finally results, interpretation and analysis. This study analyzes the historical, monthly, seasonal and annual rainfall

*Corresponding author's ORCID ID: 0000-0002-6362-4166 DOi: https://doi.org/10.14741/ijmcr.v6i01.10904 variability in Machakos sub County. The study findings are expected to help in formulating strategies to counter the problems of rainfall variability.

\subsection{Background to the Study}

Rainfall variability is the degree to which rainfall amounts vary across an area or over a given period of time. When this variation of rainfall amounts is taken at various locations across a region for a specific time, it is referred to as areal variability. Where the variation of rainfall amounts is taken at one location over a specified period of time, it is known as temporal variability. For the purposes of this study, the variability considered is temporal variability as the study area, is one area, Machakos sub County. Temporal dispersion in rainfall can 
be either from month to month, season to season or from year to year, from the long term average. This variability can cause drought or floods (Ribot et al., 1996). Rain fed agriculture in the affected areas suffers in terms of reduced yields, crop failure and to extremes livestock deaths. Subsistence crop production becomes uncertain (Medug, 2009)

Rainfall in many parts of the world is subject to variability and uncertainty as a result of fluctuations. According to Jose (2007), climate change has made rainfall in the tropical regions of the world more irregular. It used to start raining in October and continue in July every year in the Brazilian Semi-Desert region that currently suffers from drought. Today rainfall in this Brazilian region is unpredictable, streams are disappearing and water available for agriculture has drastically reduced. An elaborate analysis of annual, seasonal and monthly rainfall of 16 rainfall stations over a period of 30 years between 1960 - 1990, was conducted in India. The results revealed high variability patterns across the country. The impact of the variability was seen in terms of environmental issues like desertification in northwestern India, river channel changes over the Gangetic plains and rising trend in surface temperature variation over the whole country (Nityanand, 2009). A study conducted by Phillips et al., (1999) stated that the effects of rainfall variability have continued to affect global food production throughout history. Rainfall variability in Australia has adversely affected the eastern part of the country with the effects of expanding the desert condition (Nicholls et al., 1977).

Rainfall variability has led to expansion of the Sahara desert and encroachment of savannah and steppes lands (Ngaira, 1999). Rainfall variability has been common in many regions of Africa including the Sahel South of Sahara, West, East and Central Africa. Many countries of the Sahelian region of Africa such as Burkina Faso, Mali and Sudan are today affected by prolonged droughts adversely affecting crop yields (Ominde and Juma, 1991). A close study of documented rainfall datasets reveal that rainfall variability in Southern Africa experienced significant modifications affecting agricultural activities (Richard, 2000). In West Africa, a study by (Gribin, 1975), indicated that the area experienced prolonged droughts, which were responsible for decline in agricultural harvests. African countries are the most vulnerable to rainfall variability as they mostly depend on rain fed agriculture for their livelihood (Alberto, 2013).

Inter annual rainfall variations in equatorial East Africa are tightly linked to the Elnino Southern Oscillations (ENSO) with more rain and flooding during elnino and droughts during lamina years both having severe impact on human habitation and food security (Gerald,2011). Many areas of East African countries suffer from excessive and deficient rainfall with frequent occurrences of drought and floods. It is characterized by extreme variability of rainfall amounts with patterns of rainfall changing over different periods and causing fluctuating subsistent crop production (Shongwe, et al., 2009).

Kenya's rainfall is characterized by variability in the annual total and considerable uncertainty in the time of the year the rains are expected (Ngaira,1999). This is mainly witnessed in marginal areas like Garisa, Mandera, Magadi, Kajiado, Samburu and Machakos which are semi arid (Ojany and Ogendo,1973). A study conducted by Ovuka (2016) analyzed rainfall trends of the Central highlands of Kenya, between 1972 - 2012. Results indicated that rainfall decreased over the 40 year period and that extreme fluctuations were recorded between 2000 - 2012. The drought periods elongated over the same period adversely impacting on agricultural production. A study by Sisanya et al.(2016) on semi arid lands in Kenya, indicated that variability is persistent in the arid and semi arid lands of Kenya including Machakos and continues to affect vegetation condition and consequently crop production.

Machakos sub county receives erratic and unpredictable rain, less than $500 \mathrm{~mm}$ per annum in the southern lowlands. The higher areas towards the North and North West receive more rainfall (slightly above $1000 \mathrm{~mm}$ ) than the lowland areas in the Southern parts (less than $500 \mathrm{~mm}$ ) and particularly those in the rain shadow of the hills in the East. The rainfall is associated with erratic patterns and fluctuations in distribution over different years. Droughts are a common feature in the district with records revealing an occurrence of 4 out of 10 years (GOK, 2013). Studies conducted on rainfall variability in Machakos District such as Michael and Tiffen (1992) mainly cover the period $1930-1990$. They also cover broad large areas of South Eastern Kenya and Machakos County. The current study covers the period 1990 - 2014 and focuses on Machakos sub county which was the Central Division of the former larger Machakos District, currently Machakos County.

\subsection{Statement of the Problem}

Rainfall variability is a global predicament that impedes the success of farming activities, particularly in marginal areas. High intensities of rainfall such as that above 2,000 mm per annum cause floods as those experienced in the Gangetic plains of Asia, Congo basin and parts of Kenya including Tana delta, Kano plains, Budalangi and Athi-kapiti plains where Machakos County falls (Mburu, 2011). Low intensities particularly below $500 \mathrm{~mm}$ per annum cause drought and desertification in the affected areas (Ngaira,1999).

Kenya's rainfall is characterized by variability in the annual total and considerable uncertainty in the time of the year when the rains eventually are expected. Machakos Sub County receives erratic and unpredictable rainfall, less than $500 \mathrm{~mm}$ per annum in the Southern lowlands and between $700 \mathrm{~mm}-1000 \mathrm{~mm}$ in the hilly northern parts. The rainfall is associated with erratic patterns and fluctuations in distribution over different 
years. Droughts are a common feature in the district with records revealing an occurrence of 4 out of 10 years. Droughts disrupt farming calendars and activities; hence reduce crop and livestock yields, sometimes crop failure resulting into low harvests and food shortages especially in arid areas such as Machakos Sub County. Knowledge on rainfall variability patterns and trends will enable economic planners, the government and farmers to formulate alternative ways of adapting and mitigating the effect of rainfall variability in the study area.

Studies conducted on rainfall variability in Machakos sub County such as Michael and Tiffen (1992) and Chisanya (2011) have not given detailed analysis such as historical rainfall variability patterns and trends at monthly, seasonal and annual scales. The current study focused on historical rainfall variability and measurement in terms of distribution patterns, drought intensity, relative variability, coefficient of variability and precipitation concentration index on monthly seasonal and annual basis in Machakos Sub county. In addition, these previous studies mainly cover the period 1930 1990. The current study covers the period $1990-2014$ This period of 25 years is adequate to determine rainfall variability and climate of the area.

\subsection{Objective of the study}

The objective of the study was to establish the historical rainfall variability at monthly seasonal and annual scales in Machakos Sub County between 1990 - 2014.

\section{Literature Review}

\subsection{Introduction}

Rainfall is an important element of both weather and climate (Ngaira, 1999). Rainfall is the most important element determining climate. Broad divisions of climatic types of the world have been based on rainfall and temperature Karugah and Kibuuka, (2003). Rainfall variability refers to the degree to which rainfall amounts vary across an area or over a given period of time. The variation of the amounts at various locations across a region for a specific time interval is known as areal variability and when the variation of the amount is at a particular location, within a given period of time, is called temporal variability (Nicholls et al., 1997). Assessing rainfall variability is a frequent practice in climatology. An important application is the estimation of total rainfall over an area e.g. catchment area as an input of climatic models (Wenner, 2012).

\subsection{Rainfall Distribution, Patterns and Variability}

2.2.1 Distribution, patterns and Variability at global, regional, and local levels

Precipitation, particularly rainfall is in many cases the most important input factor in a climatological modeling
(Wenner, 2012). However this input is subject to uncertainty as a result of fluctuations (variability), measurement errors and systematic errors in the interpolation method, due to random nature of rainfall (Barrow, 2003). Rainfall in many parts of the world is subject to variability and uncertainty as a result of the fluctuations. According to Jose (2007), climate change has made rainfall in the tropical regions of the world more irregular. It used to start raining in October and continue in January every year in the Brazilian semi-desert region that currently suffers from drought. Today rainfall in this area is unpredictable, streams are disappearing and water available for agriculture has drastically reduced.

Rainfall variability has led to expansion of the Sahara desert and encroachment of the savannah and steppes land during modern times. Remarkable fluctuations of rainfall have occurred over nearly the entire continent (Ojany and Ogendo, 1973). Rainfall variability has been common in the Sahel south of Sahara, East and Central Africa. Kenya's rainfall is characterized by variability in the annual total and considerable uncertainty in the time of the year when the rains are expected (Ngaira, 1999). This is mainly witnessed in marginal areas like Garissa, Mandera, Suguta plains, Magadi, Machakos, among others.

The above studies have generalized rainfall variability covering broad and large regions of the world prompting the need to focus on a smaller area within a country. Environmental and rainfall patterns differ from one area to another within or outside a country (Ovuka, 2016). Generalizing rainfall patterns for the whole country or region does not provide adequate understanding of rainfall variability in a given particular area (Richard, 2003). This study focused on a small area in Kenya's semi arid lands, Machakos sub County. Studies on the mean annual rainfall of Kenya reveal the general inadequacies of the amounts of rainfall received by large parts of the country. This is clearly revealed in Table 2.1. Drought is one of the most basic problems of development in Kenya. Two other characteristics of this rainfall are also important but not apparent from the maps. There are wide variability in the annual total and considerable uncertainty in the time of the year when the rains can be expected. Planned agriculture is therefore made difficult to carry out (Ojany and Ogendo, 1973).

Table 2.1 Rainfall Distributions in Kenya 1973

\begin{tabular}{|c|c|c|c|}
\hline $\begin{array}{c}\text { Rainfall in } \\
\mathbf{m m}\end{array}$ & Area in $\mathbf{~ m}^{\mathbf{2}}$ & $\begin{array}{c}\text { \% of Total } \\
\text { Area }\end{array}$ & $\begin{array}{c}\text { Cum } \\
\text { percentage }\end{array}$ \\
\hline $0-253$ & 157470 & 27.0 & 27.0 \\
\hline $254-507$ & 209011 & 35.9 & 62.9 \\
\hline $508-761$ & 105692 & 18.1 & 81.0 \\
\hline $762-1015$ & 48692 & 8.4 & 89.4 \\
\hline $1016-1269$ & 28490 & 4.9 & 94.6 \\
\hline $1270-1523$ & 19425 & 3.3 & 97.6 \\
\hline $1524-1777$ & 9583 & 1.6 & 99.9 \\
\hline $1778-2031$ & 3885 & 0.7 & 99.9 \\
\hline $2032+$ & 518 & 0.1 & 100.1 \\
\hline \multicolumn{4}{|c|}{ Source Ojany and Ogendo, 1973 } \\
\hline
\end{tabular}

26 | Int. J. of Multidisciplinary and Current research, Vol.6 (Jan/Feb 2018 
The reasons for this large rainfall variations is partly, the tremendous topographical contrasts, including great altitudinal range and partly the distribution and presence of large water bodies such as lake Victoria (Karugah and Kibuuka, 2003). The alternate cooling and heating of the lake and surrounding land initiates on shore and off shore breezes. The prevalent easterly winds meet the land breezes and the two bring about subsidence of air and hence small amounts of rainfall. This is the reverse of the western shores. Prominent topographical features stand out as highlands or pockets of high topographic points initiating rainfall (Ojany and Ogendo, 1973). A more serious drought however characterizes the Northern and North Eastern Kenya which is in fact, part of the dry region that covers North Eastern Africa and Arabia (Minns, 1984). Table 2.1 shows rainfall distribution in Kenya. It shows that $27 \%$ of Kenya is arid and $40 \%$ of the total land area is semi arid and that a smaller area (10\%) receives over $1000 \mathrm{~mm}$. This clearly shows the high variabilities of rainfall across the country.

The study area, Machakos sub County receives erratic and unpredictable rain, less than $500 \mathrm{~mm}$ per annum in the southern lowland areas. Rainfall varies with altitude. The hilly northern parts receive high rainfall between $700 \mathrm{~mm}-1000 \mathrm{~mm}$ per annum. The rainfall has abnormal patterns with a significant difference in distribution over different years. The short rains occur in March to May/June (MAMJ) while the long rains fall in October to December/Jan (ONDJ), although it is not very reliable. Historical data indicates that in 4 out of 10 years, there is a major drought in the district (GOK, 2013). The above studies have focused on annual and monthly rainfall distribution patterns and left out other characteristic aspects of measurement of rainfall variability such as Distribution patterns (DP), Drought intensity (DI), Relative variability (RV), Coefficient of variability (CV) and Precipitation concentration index $(\mathrm{PCl})$ that makes deeper understanding of rainfall variability of an area. The current study analyses the rainfall variability of Machakos sub County focusing on all the above aspects and measurement of rainfall variability.

\subsubsection{Distribution and Variability of rainfall in Marginal areas}

Marginal areas refer to transitional zones from one climate type to another climate type. They are broad zones of transition where climatic characteristics of one type progressively merges into those of the next zone (Karugah and Kabuuka, 2003). Most of the Eastern Kenya falls in this transitional zone called marginal areas. Temperatures are high throughout the year ranging between $21^{\circ} \mathrm{C}-26^{\circ} \mathrm{C}$. The mean annual temperature is low $5^{\circ} \mathrm{C}$. Rainfall is low and variable and generally rarely exceeds $500 \mathrm{~mm}$ annually. The rainfall patterns and amounts are extremely variable (Ojany and Ogendo, 1973). The term marginal area is generally applied to farming the marginal lands (not as good as the prime land) that farmers use when demand is exceeding supply and prime land is at maximum capacity. Marginal land will produce less per acre than prime land, but it will realize a profit if demand is high (Jose, 2007).

According to Jude (2007), marginal environments can be defined as areas where agriculture is dominated by variations in agro ecological and socio-economic conditions. Such heterogeneous and erratic climatic conditions, variable topography results in complex stress and high production risks. The heterogeneity of the environment where these farming activities take place, a research develops that produces diverse products such as crop varieties adapted to low fertility and erratic climatic conditions which also produce well under limited inputs (Mitchelle, 2007). Rural development in marginal areas initiate projects that improve the well being and incomes of small holders (Jude, 2007). Extreme variations of patterns and totals of rainfall are responsible for extreme weather conditions like droughts and floods. Droughts and floods are common features of the Kenyan climate. Both these extremes are due to rainfall anomalies and cause great difficulty for an essentially agricultural people in Kenya who have to farm large marginal areas (Mburu, 2011). The above studies have covered large expansive areas and regions giving generalized focus on broad marginal areas. A study made in a small area will provide detailed, exact, clear and precise results. The current study sought to address this problem by focusing on a smaller marginal area, Machakos sub County in Eastern Kenya.

\subsection{Time Series Analysis Technique of long term rainfall trends}

Monthly or annual variability statistics do not reveal the trends or time sequence of rainfall occurrence. Hence the need to use a more appropriate method that can analyze long term trends of rainfall in particular years. This method is called Time series analysis technique (Nicholson, 1989). Domonkos (1993) analyzed time series of monthly rainfall totals in Hungary between 1901 1998 to detect the long term changes in rainfall characteristics and found significant decline of annual totals by $15-22 \%$.

Analysis of annual rainfall time series by Tanzania Meteorological Agency (2000) indicated a significant decrease of rainfall trend for more of the stations but with greater variability in cycle (Alberto, 2013). In the current study, Time series data analysis technique was used to study rainfall variability patterns and trends in Machakos sub County between $1990-2014$.

\section{Methodology}

Rainfall data obtained from meteorological department headquarters in Nairobi for the sub County, focused on two weather stations namely, Kari, Katumani in Central Division and Mutisya mango farm location in Kalama 
Division. Central and Kalama are the two divisions that make up Machakos sub County. The Annual and monthly rainfall totals in the two stations of Machakos sub County were analyzed to determine their variability between 1990 and 2014.

The Annual monthly and seasonal rainfall totals in the two stations of Machakos sub County were analyzed using Time series technique to determine rainfall variability between of the two stations that represent Machakos sub County between 1990 and 2014. The following analysis techniques were used to establish various rainfall characteristics to measure and determine rainfall Variability in Machakos sub County; Drought intensity (DI) to determine the ratio of rainfall deficit to the long term mean, precipitation Concentration index (PCl) for annual and seasonal rainfall concentration; coefficient of variation $(\mathrm{CV})$ for measuring variability, Standard Deviation to determine the departure of total annual rainfall from the mean, Anomaly to show the percentage departure of annual total rainfall from the long term mean and Relative Variability (RI) to measure Variability.

\section{Results and Discussion 4.1 Introduction}

This chapter presents results, data analysis and discussion, interpretation, findings and discussions based on objective of the study. The chapter has been divided into two parts; the first part presents the analysis of historical rainfall variability at monthly and annual scales. The second part presents analysis of historical rainfall variability at seasonal scale.

\subsection{Analysis of Monthly and annual Rainfall variability in Machakos sub County 1990 -2014}

\subsubsection{Analysis of historical Monthly and Annual Rainfall totals and Means between $1990-2014$ in Central Division}

Table 4.1 below, shows the annual and Monthly rainfall totals and means of Kari centre Katumani in Centra Division for the last 25 years $(1990-2014)$.

Table 4.1 Monthly and Annual rainfall Mean and total for Kari Center Katumani, Central Division, Machakos sub County $(1990-2014)$

\begin{tabular}{|c|c|c|c|c|c|c|c|c|c|c|c|c|c|}
\hline & Jan & Feb & Mar & Apr & May & Jun & Jul & Aug & Sep & Oct & Nov & Dec & Total \\
\hline 1990 & 42.8 & $23 . .2$ & 217 & 250.7 & 65.9 & 5.1 & 0.0 & 3.4 & 0.0 & 0.0 & 208.5 & 110.2 & 975.9 \\
\hline 1991 & 29.2 & 13.3 & 43.5 & 80.5 & 57.5 & 3.1 & 1.4 & 8.9 & 3.4 & 46.5 & 119.5 & 156.7 & 563.9 \\
\hline 1992 & 12.0 & 6.1 & 5.0 & 193.7 & 35.0 & 1.1 & 6.8 & 0.0 & 0.7 & 31.0 & 114.2 & 186.2 & 621.8 \\
\hline 1993 & 265.5 & 84.9 & 60.9 & 20.8 & 13.7 & 6.3 & 0.5 & 3.1 & 0.6 & 26.0 & 150.8 & 152.5 & 776.6 \\
\hline 1994 & 0.0 & 103.5 & 70.3 & 83.6 & 29.8 & 8.2 & 3.3 & 9.9 & 4.3 & 116.9 & 308.2 & 143.7 & 881.7 \\
\hline 1995 & 28.5 & 83.5 & 150.1 & 49.6 & 33.0 & 0.9 & 4.1 & 3.2 & 5.1 & 103.7 & 46.6 & 87.4 & 595.5 \\
\hline 1996 & 22.4 & 56.5 & 73.7 & 96.4 & 42.8 & 19.3 & 2.2 & 2.2 & 0.7 & 0.0 & 187.7 & 1.5 & 505.4 \\
\hline 1997 & 3.8 & 0.0 & 46.0 & 208.5 & 21.5 & 0.5 & 1.2 & 4.3 & 0.0 & 83.2 & 270.3 & 117.3 & 816.3 \\
\hline 1998 & 295.4 & 219.5 & 118.0 & 123.0 & 162.6 & 38.7 & 15 & 2.9 & 1.8 & 0.0 & 113.9 & 15.8 & 1106.9 \\
\hline 1999 & 16.0 & 2.2 & 121.0 & 113.8 & 9.8 & 2.4 & 4.9 & 0.0 & 5.0 & 20.6 & 257 & 108.6 & 661.3 \\
\hline 2000 & 7.0 & 0.0 & 53.3 & 68.5 & 15.6 & 6.2 & 0.3 & 1.8 & 2.3 & 41.0 & 181.9 & 99.7 & 485.6 \\
\hline 2001 & 244.5 & 0.0 & 113 & 88.9 & 15.3 & 4.3 & 4.3 & 2.5 & 0.0 & 7.3 & 169 & 43.6 & 693 \\
\hline 2002 & 79.5 & 7.5 & 89.0 & 120.4 & 126.1 & 1.4 & 0.0 & 0.2 & 8.8 & 21.2 & 144.3 & 182.4 & 780.8 \\
\hline 2003 & 31.6 & 17.2 & 115.2 & 153.2 & 133.8 & 0.0 & 0.0 & 26.3 & 21.5 & 30.8 & 121.1 & 24.1 & 674.8 \\
\hline 2004 & 48.0 & 47.9 & 83.1 & 121.5 & 59.8 & 0.7 & 0.0 & 0.0 & 1.0 & 47.6 & 161.3 & 89.5 & 660.4 \\
\hline 2005 & 12.2 & 19.2 & 101.7 & 165.1 & 100.5 & 0.0 & 0.0 & 1.5 & 0.0 & 8.4 & 93.4 & 112.8 & 614.8 \\
\hline 2006 & 30.9 & 53.1 & 105 & 175.9 & 106.7 & 2.4 & 0.6 & 17.5 & 2.1 & 10.7 & 328.4 & 321.3 & 1154.6 \\
\hline 2007 & 61.4 & 44.8 & 205 & 143.9 & 41.7 & 2.7 & 27 & 5.2 & 4.3 & 18.3 & 128.2 & 82.4 & 764.7 \\
\hline 2008 & 117.4 & 7.3 & 73 & 129.3 & 4.5 & 0.3 & 1.3 & 0.2 & 9.1 & 23.9 & 112.8 & 39.9 & 529.0 \\
\hline 2009 & 74.2 & 26.3 & 3.2 & 145.4 & 29.7 & 5.2 & 0.0 & 0.0 & 1.2 & 41.3 & 34.4 & 129.1 & 488.0 \\
\hline 2010 & 57.1 & 64.1 & 232 & 107.9 & 120.9 & 1.4 & 2.7 & 1.3 & 0.6 & 29.3 & 116 & 125.4 & 858.7 \\
\hline 2011 & 9.1 & 71.8 & 209.8 & 1.0 & 37.8 & 27.3 & 3.4 & 0.7 & 5.9 & 50.2 & 232.5 & 28.2 & 677.7 \\
\hline 2012 & 14.7 & 4.6 & 1.6 & 286.7 & 205 & 36.9 & 3.3 & 0.4 & 4.5 & 22.3 & 119.7 & 173.2 & 872.9 \\
\hline 2013 & 22.4 & 43.3 & 96.3 & 184.4 & 234.4 & 4.1 & 3.2 & 11.4 & 0.2 & 33.1 & 123.5 & 54.2 & 810.5 \\
\hline 2014 & 32.6 & 12.1 & 124.6 & 235.3 & 185.3 & 22.4 & 1.4 & 4.0 & 1.9 & 50.0 & 124.0 & 34.5 & 828.1 \\
\hline TOTAL & 1549.5 & 1012 & 2512 & 3348 & 1888 & 204 & 85 & 116 & 80.0 & 912.1 & 4015.6 & 2678.2 & 18399 \\
\hline MEAN & 62.0 & 40.5 & 100.5 & 133.9 & 75.5 & 8.1 & 3.4 & 4.6 & 3.2 & 36.5 & 160.6 & 107.1 & 736.0 \\
\hline
\end{tabular}

Source. Kari Center Katumani, Weather Station (2015)

Table 4.1 reveals the erratic (Unpredictable/Not entirely certain) rainfall patterns in semi arid Central Division. Rains failing when they are expected and coming when they are least expected. The table shows monthly and annual rainfall totals in Central Division. In the semi arid Central Division, the known dry months were June, July,
August and September when the long term mean monthly rainfall was below $10 \mathrm{~mm}$. A monthly mean of below $10 \mathrm{~mm}$ indicates a dry month. If continuous it culminates into drought. In some years, these dry months received totals above the monthly long term mean such as June 1996, 1998, 2011, 2012 and 2014. July 2007, 1999 
and 1992. August 2003, 2006, and 2013. September 2003 and 2008.

The designated wet months were March (100.5) to April (133.9) and November with a mean of $160.6 \mathrm{~mm}$ and December with a mean of $107.1 \mathrm{~mm}$. as shown on Table 4.1. Some months in the designated wet months received very low or no rainfall below $50 \mathrm{~mm}$. such as March 1992, 2009 and 2012, April 2011, 1994 and 1993. November 1995 and 2009. December 1996, 1998, 2003 and 2011. On many occasions the rains failed in the time they were expected, only to come the time they were least expected such as in 1992, 2009 and 2012 they were expected in March. In 1993, 1998, 2001, 2008 January received very heavy rains that were not expected. This rainfall pattern was erratic/unpredictable to create anxiety and uncertainty among the inhabitants. The Variability of rainfall in amounts was shown in mean monthly rainfall in Kari Katumani station of Central Division. Monthly mean rainfall of $10 \mathrm{~mm}$ is too low. If continuous it becomes a true arid condition.

Central Division lies near the high areas in the northern parts which receives higher rainfall. This kind of rainfall was erratic or unpredictable. Monthly rainfall below $50 \mathrm{~mm}$ indicates a dry month. If continuous becomes drought. A similar study carried out in Kahangara Division in Northern Tanzania by Alberto (2013), showed that rainfall was highly variable and unpredictable in terms of onset and totals. The results are similar with the current study with differences coming in the months the wet and dry spells occurred in the two areas. In Kahangara the wet season was from October to May and the dry season was between June and August. A study by Nicholson (2000) sought to assess rainfall variability in Eastern Africa between 1950 and 1980. Results indicated an annual declining trend with increasing variability. The results are similar to those of the current study. The difference is that the current study focuses on a small area which gives actual specific results compared to a large area which gives more general results.

The erratic nature of rainfall in Machakos sub Coumty is almost similar to that of semi arid Baringo District in Ngaira's (1999) study. Baringo recorded seven years, when the rains were low or failed during the expected rainy season, compared to Machakos which recorded four years. Moreover, the annual rainfall trend was analyzed to find out the general fluctuations and trends of the rainfall totals over the 25 year period as shown in Figure 4.1.

Figure 4.1 shows the characteristics and trends of annual total rainfall in Central Division for the period $1990-2014$

From the figure, the highest annual total was 1154 $\mathrm{mm}$, recorded in 2006 followed by $975.9 \mathrm{~mm}$ which was recorded in 1998 and 1990 . The lowest rainfall totals (562.9 mm). were recorded in 1991, $505.4 \mathrm{~mm}$. in 1996, 2000 (485.56 mm) and 2009 (488.0 mm). A comparison made from Table 4.1, The highest disparities were recorded between 2005 - 2016 (539 mm), 1998 - 1999 (445 mm) and 1990 - 1991 (412 mm). The lowest disparities were recorded in $2003-2004$ (106mm), 2012 - 2013 (95.2mm) and $2013-2014$ (62.4mm).

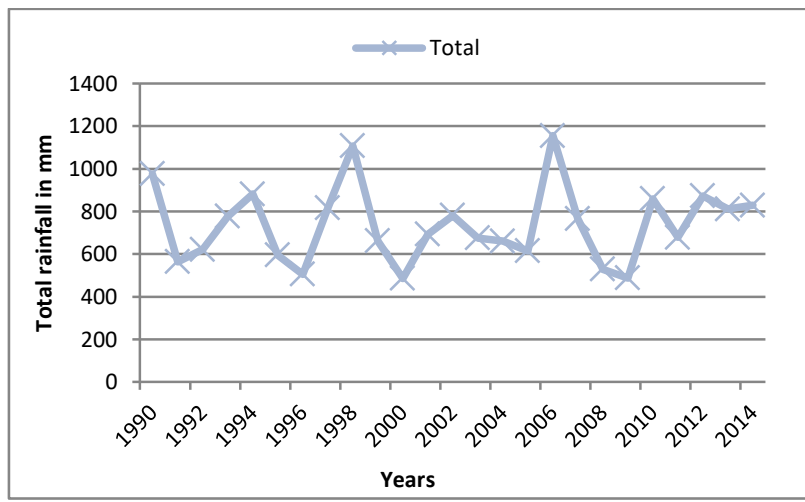

Figure 4.1: Annual Total and trends for the period 1990 2014. Kari Katumani (Central Division)

High disparities imply high variability in Machakos sub County, the study area. According to Alberto ( 2013) Kahangara Division, has high variability of annual total rainfall with some years having more rainfall than others. Normal rainfall is less likely in this area, though there are still chances that it can occur once within four years. Chances of normal rainfall occurring are higher (2/3) in Central Division of Machakos sub County as compared to Kahangara Division as shown in the distribution patterns on Figure 4.1.

The fluctuating patterns over the twenty five year period 1990 - 2014 (Figure 4.1) was an indication of a high rainfall variability year to year in the sub County. Central Division is wetter towards the hilly northern parts. This gives the reason why coffee and maize are mainly grown in Central Division particularly in the hilly Northern and North Eastern parts. The long term mean rainfall was $736 \mathrm{~mm}$ over the twenty five year period. Eleven out of twenty five years recorded totals below the long term mean. It is only during the Elnino rains, such as those of 1997 (October - November) and 2015 (March to June) that high continuous rainfall was experienced favoring fast maturing crops like beans, vegetables and katumani maize.

Similar results have been reported by Nicholson (2000) who assessed climate variability in Eastern Africa 1950 s to 1980 s and findings revealed that rainfall trends had high fluctuations and continuous reduction in their totals. Time series study of rainfall (1960 - 2002) by Ngongondo (2005) in Malawi, had similar results as those of this study. It revealed significant departures from the mean hence variability.

\subsubsection{Analysis of Monthly and Annual Rainfall totals and Means between 1990 - 2014 in Kalama Division}

The Table 4.2 below shows the historical monthly and annual rainfall totals and means of Mutisya Mango farm in Kalama Division of Machakos sub County. This is the 
second station that falls under the analysis of the current study area which was used to establish the rainfall variability patterns in the study area.

Kalama Division which is a lowland area lying towards the east, has more months with no rainfall (52) than Central Division (18), hence it is drier. The eastern side of Kalama lies in the rain shadow of Makueni hills. June to September received below a long term mean of $10 \mathrm{~mm}$ but there were cases when these designated dry months received totals above a long term mean of $10 \mathrm{~mm}$ that is in June 1995, 1996, 1998, 2001 and 2012; July 1994, 1998, 2001, 2007 and 2012; August 1991, 1995 and 1999; September 1994. The wet months in Kalama Division are April (Long term mean of $104 \mathrm{~mm}$ ) and November (Long term mean of $153 \mathrm{~mm}$ ). Cases where a total of less than $50 \mathrm{~mm}$ was experienced in these wet months were in April 1993, 1996, 2001, 2008, 2012 and 2013; November 2009, 2011, 2012 and 2013 as seen in Table 4.2. In Kalama
Division (Mutisya mango farm location) the driest months are August with a mean of $3.4 \mathrm{~mm}$ June (4.9), July (5.9) and September with a mean of $2.1 \mathrm{~mm}$. The wettest months are April with a mean of $104 \mathrm{~mm}$ and November with a mean of $153 \mathrm{~mm}$ which is similar to Central but differing in amounts and occasionally receiving less than $50 \mathrm{~mm}$ of rainfall. This differs from those of Kahangara Division in Tanzania where the wettest months were October and April. The high rainfall periods in the study area are short lived and the short rainfall periods are long, meaning more drought periods. Analysis of annual rainfall provides significant insights of the growing seasonal rainfall variability. The analysis provide a general understanding of the patterns which may provide guidelines on planning farming activities. Comparing results with related studies also helps us to evaluate our own work and guides us more to appreciate our findings.

Table 4.2: The Historical Monthly and Annual Rainfall totals and Means of each year for 25 years (1990 - 2014) Kalama Division

\begin{tabular}{|c|c|c|c|c|c|c|c|c|c|c|c|c|c|}
\hline Year & Jan & Feb & Mar & Apr & May & Jun & July & Aug & Sept & Oct & Nov & Dec & $\begin{array}{c}\text { Totals } \\
\text { Rainfall }\end{array}$ \\
\hline 1990 & 51.4 & 29.7 & 154 & 202 & 23.0 & 0.0 & 6.6 & 1.8 & 0.0 & 34 & 203 & 151. & 856.9 \\
\hline 1991 & 123 & 2.3 & 70.0 & 89.4 & 53.6 & 7.7 & 3.8 & 15.6 & 7.0 & 14 & 141 & 128 & 654.8 \\
\hline 1992 & 25.8 & 42.5 & 14.0 & 231 & 22.9 & 0.0 & 3.0 & 1.5 & 5.7 & 19 & 121 & 191 & 677.1 \\
\hline 1993 & 260 & 91.5 & 31.9 & 45.1 & 41.0 & 6.5 & 0.0 & 4.6 & 0.0 & 38 & 117 & 105 & 739.2 \\
\hline 1994 & 0.0 & 61.5 & 100 & 86.5 & 36.5 & 1.2 & 12.3 & 6.6 & 18.2 & 75 & 220 & 133. & 749.9 \\
\hline 1995 & 6.8 & 75.4 & 150. & 60.0 & 28.5 & 20.5 & 3.8 & 14.4 & 0.6 & 115 & 127 & 100. & 702.1 \\
\hline 1996 & 25.1 & 34.0 & 140 & 43.5 & 93.5 & 12.1 & 4.4 & 5.6 & 0.0 & 0.0 & 385 & 46.2 & 789.8 \\
\hline 1997 & 7.3 & 0.0 & 16.0 & 281 & 102 & 4.6 & 8.0 & 0.0 & 0.0 & 86 & 438 & 310 & 125.9 \\
\hline 1998 & 492 & 172 & 33.7 & 129 & 159 & 15.4 & 30.8 & 3.2 & 0.0 & 0.0 & 114. & 30.6 & 1180.4 \\
\hline 1999 & 52.2 & 0.0 & 23.2 & 181 & 5.0 & 0.0 & 0.0 & 10.0 & 0.0 & 27.5 & 308 & 114 & 720.1 \\
\hline 2000 & 30.9 & 0.0 & 30.1 & 123 & 21.3 & 9.5 & 8.0 & 8.0 & 7.8 & 0.0 & 166 & 86.4 & 491.1 \\
\hline 2001 & 145 & 21.0 & 106 & 42.7 & 25.0 & 11.0 & 13.0 & 2.8 & 5.2 & 13 & 220 & 9.0 & 613 \\
\hline 2002 & 82.2 & 12.0 & 99.3 & 141 & 57.2 & 0.0 & 0.0 & 6.0 & 0.0 & 40.7 & 161 & 217 & 816.8 \\
\hline 2003 & 0.0 & 13.2 & 72.0 & 151 & 121 & 0.0 & 0.0 & 0.0 & 2.5 & 48.4 & 157 & 23.2 & 558.1 \\
\hline 2004 & 29.0 & 30.5 & 59.3 & 86.4 & 23.1 & 2.0 & 0.0 & 0.0 & 0.0 & 79.4 & 75.0 & 101. & 486.1 \\
\hline 2005 & 0.5 & 36.5 & 51.3 & 93.9 & 35.1 & 0.0 & 0.2 & 0.0 & 0.0 & 11.5 & 56.7 & 5.8 & 291.5 \\
\hline 2006 & 25.4 & 41.9 & 28.7 & 175 & 44.8 & 0.0 & 2.4 & 0.0 & 0.0 & 26 & 218 & 160 & 721.8 \\
\hline 2007 & 39.7 & 8.7 & 29.0 & 64.8 & 27.1 & 4.1 & 14.2 & 2.3 & 2.3 & 36 & 129 & 31.9 & 388.8 \\
\hline 2008 & 60.5 & 0.0 & 70.5 & 23.4 & 0.0 & 0.0 & 1.2 & 0.0 & 0.0 & 17 & 131 & 5.2 & 308.7 \\
\hline 2009 & 28.4 & 0.0 & 25.6 & 75.5 & 29.6 & 0.0 & 0.0 & 0.0 & 0.0 & 37 & 34.1 & 101 & 331.1 \\
\hline 2010 & 51.5 & 69.2 & 55.4 & 60.2 & 71.8 & 0.0 & 0.0 & 0.0 & 0.0 & 20 & 144 & 12.5 & 484.5 \\
\hline 2011 & 6.2 & 21.2 & 80.4 & 55.6 & 24.0 & 2.1 & 0.0 & 2.1 & 0.0 & 23 & 12.4 & 96.0 & 353.1 \\
\hline 2012 & 64.2 & 40.5 & 75.2 & 30.0 & 12.4 & 12.3 & 23.2 & 0.0 & 0.0 & 42 & 45.0 & 200 & 544.9 \\
\hline 2013 & 25.6 & 15.8 & 54.7 & 44.0 & 54.5 & 5.7 & 0.0 & 1.4 & 1.2 & 49 & 21.2 & 65.2 & 338.3 \\
\hline 2014 & 94.4 & 56.0 & 42.3 & 85.9 & 66.0 & 7.3 & 13.2 & 0.0 & 2.5 & 56.7 & 76.4 & 65.0 & 565.7 \\
\hline Totals & 1757 & 876 & 1612 & 2600 & 1178 & 122 & 148 & 85.9 & 53.0 & 908 & 3818 & 2487 & 1564.67 \\
\hline Mean & 70.3 & 35.0 & 64.5 & 104 & 47.1 & 4.9 & 5.9 & 3.4 & 2.1 & 36.4 & 153 & 99.5 & 625.9 \\
\hline
\end{tabular}

Source. Mutisya mango farm location. Weather Station (2015)

Variability in Kalama Division is very high since the total number of years receiving less than $50 \mathrm{~mm}$ in April are 7/12. A wet month was recorded in nine years. Central recorded wet months in five years. The wettest month in Central recorded a mean of $160 \mathrm{~mm}$ where as in Kalama the wettest month recorded a mean of $99.5 \mathrm{~mm}$. The long term mean of Kalama is 625.9 and Central Katumani is 736. The driest months in Kalama were August $(3.4 \mathrm{~mm})$ and September $(2.1 \mathrm{~mm})$ and in Central Division. (July $3.4 \mathrm{~mm})$ and September $(3.2 \mathrm{~mm})$ This implies that Kalama
Division was drier with a higher variability. Nicholson's (1989) study of climate variability in East Africa 1950s to 1980s reported similar results with results revealing that rainfall trends had high fluctuations implying high variability.

A study carried out on effects of drought in semi arid Laikipia District by Mburu (2011) also revealed high variability and fluctuations in rainfall totals and trends. Laikipa lies to the west of the Central highlands while Machakos lies to the East of the Central highlands. 
Kahangara Division in Tanzania recorded two wet months. These two high rainfall months were October and may (Alberto, 2013). The differences could be attributed to topographical differences and the geographical position of the two areas. Kahangara is close to lake Victoria, where the influence of land and lake breezes could modify the micro- climate of the area. Machakos sub County is close to the hill massifs of Iveti, Mua and Kangundo that attacts more rainfall in the Northern parts of the Sub County Making them wetter than the lower southern parts. The eastern part lies in the rain shadow of Kitui hills.

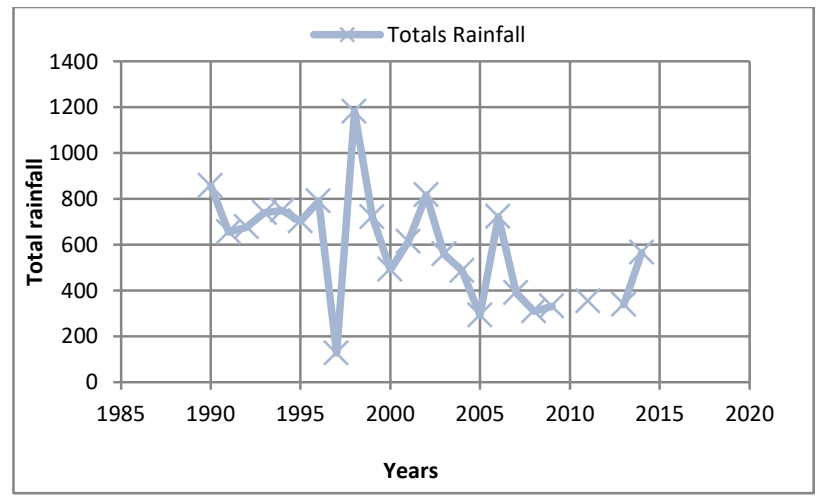

Figure 4.2: Rainfall totals for the period $1990-2014$. Mutisya farm station (Kalama Division)

Moreover, the annual rainfall trend was analyzed as shown in Figure 4.2 below to find out the general fluctuations and trends of the annual rainfall totals in the Kalama Division for the 25 year period. From the results in Figure 4.2, the highest annual total was recorded in 1998 $(1180.4 \mathrm{~mm})$ followed by $1990(856.9 \mathrm{~mm})$ and 2002 $(816.8 \mathrm{~mm})$. The lowest rainfall totals were recorded in 2009 (331.1mm), 2008 (308.7 mm), 2005 (291.5 mm) and 1997 (125.9 mm. The highest disparities were recorded between 1997 - 1998 (1054.5 mm), 2006 - 2005 (430.3 $\mathrm{mm}$ ) and $2002-2003(258 \mathrm{~mm})$. These conditions can be attributed to the Elnino and lanina effects of 1997/98 and the prolonged droughts experienced after four years. The lowest disparities were recorded in 1995 - 1996 (87.7mm), 1992 - 1993 (62.1mm) and 1993 - 1994 (10.7 $\mathrm{mm}$ ). This can be attributed to a long dry spell in average rainfall $1992-1995$.

The fluctuating patterns over the twenty five year period 1990-2014 is a clear indication of a high rainfall variability in the Division. Table 4.1 and table 4.2 shows monthly, annual, rainfall totals and means to determine variability in the two rainfall stations that provide rainfall data for Machackos sub County. Generally Kalama Division is drier (overall long term mean of $625 \mathrm{~mm}$ ). Equally it has more erratic rainfall as evidenced in the higher variability. A mean annual rainfall of $500 \mathrm{~mm}$ $750 \mathrm{~mm}$ indicates semi arid and below $500 \mathrm{~mm}$ to indicates drought condition. Kalama Division recorded more severe semi arid conditions with many years recording below $500 \mathrm{~mm}$. In Central Division most years recorded above $750 \mathrm{~mm}$. These conditions make Kalama Division to have more severe and harsh drought conditions, leading to adverse crop failure and lower harvests. A similar study was conducted in Baringo District by Ngaira (1999). The study made a comparison of variability between two Divisions, Marigat and Nginyang both of them revealing high erratic rainfall and anomalies in monthly distribution leading to intense drought conditions adversely affecting farming activities.

\subsection{Analysis of annual Rainfall Totals, Means, Standard deviations, Anomalies and Coefficient of Variation in Machakos sub County.}

Table 4.3 and 4.4 shows annual totals, means, coefficient of variation and anomalies of each year recorded over the 25 years (1990 - 2012) in Katumani (Central Division) and Mutisya (Kalama Division) respectively. Formulas used to calculate each of the above variables have been clearly shown.

Table 4.3 Monthly Rainfall totals, Annual Rainfall totals, Means, Standard deviations, Anomalies and Coefficient of variation of each year over 25 years. $(1990-2014)$. Katumani Kari. Central Division, Machakos District

\begin{tabular}{|c|c|c|c|c|}
\hline Year & $\begin{array}{c}\text { Total } \\
\text { rain fall }(\mathrm{mm})\end{array}$ & Mean & $\begin{array}{c}\text { Std } \\
\text { Deviation }\end{array}$ & $\begin{array}{l}\text { Anom } \\
\text { Alies }\end{array}$ \\
\hline 1990 & 975.9 & 81.3 & 93.15 & 20 \\
\hline 1991 & 563.9 & 47.0 & 49.914 & -30 \\
\hline 1992 & 621.8 & 51.8 & 75.801 & -20 \\
\hline 1993 & 776.6 & 64.7 & 81.905 & 10 \\
\hline 1994 & 881.7 & 73.5 & 89.567 & 20 \\
\hline 1995 & 595.5 & 49.6 & 47.574 & -20 \\
\hline 1996 & 505.4 & 42.1 & 56.066 & -50 \\
\hline 1997 & 816.3 & 68 & 96.278 & 10 \\
\hline 1998 & 1106.9 & 92.2 & 97.121 & 30 \\
\hline 1999 & 661.3 & 55.1 & 79.674 & -10 \\
\hline 2000 & 485.6 & 40.5 & 57.132 & -50 \\
\hline 2001 & 693 & 57.8 & 80.550 & -10 \\
\hline 2002 & 780.8 & 65.1 & 66.409 & 10 \\
\hline 2003 & 674.8 & 56.2 & 56.681 & -10 \\
\hline 2004 & 660.4 & 55.0 & 52.043 & -10 \\
\hline 2005 & 614.8 & 51.2 & 58.961 & -20 \\
\hline 2006 & 1154.6 & 96.2 & 119.68 & 40 \\
\hline 2007 & 764.7 & 63.7 & 64.560 & 0 \\
\hline 2008 & 529.0 & 44.1 & 52.146 & -40 \\
\hline 2009 & 488.0 & 40.7 & 49961 & -50 \\
\hline 2010 & 858.7 & 71.6 & 71.386 & 10 \\
\hline 2011 & 677.7 & 56.5 & 80.099 & -10 \\
\hline 2012 & 872.9 & 72.7 & 98.711 & 20 \\
\hline 2013 & 810.5 & 67.5 & 77.046 & 10 \\
\hline 2014 & 828.1 & 69.0 & 79.132 & 10 \\
\hline TOTALS & 18399 & & & \\
\hline MEAN & 736.0 & & & \\
\hline $\begin{array}{l}\text { STD } \\
\text { DEV }\end{array}$ & 178.88 & & & \\
\hline C.V & 0.24 & & & \\
\hline
\end{tabular}

Source. Katumani Kari Cente Weather Station (2015)

31 | Int. J. of Multidisciplinary and Current research, Vol.6 (Jan/Feb 2018) 
Table 4.4 Monthly Rainfall totals, Annual Rainfall totals, Means, Standard deviations, Anomalies and Coefficient of variation of each year over 25 years. (1990-2014). Mutisya mango farm location. Kalama Division, Machakos District

\begin{tabular}{|c|c|c|c|c|}
\hline Year & $\begin{array}{c}\text { Total } \\
\text { rain fall }(\mathrm{mm})\end{array}$ & Mean & $\begin{array}{c}\text { Std } \\
\text { Deviation }\end{array}$ & $\begin{array}{l}\text { Anom } \\
\text { Alies }\end{array}$ \\
\hline 1990 & 856.9 & 71.4 & 81.3 & 0 \\
\hline 1991 & 654.8 & 54.6 & 53.9 & 0 \\
\hline 1992 & 677.1 & 56.4 & 9.6 & 10 \\
\hline 1993 & 739.2 & 61.6 & 74.5 & 20 \\
\hline 1994 & 749.9 & 62.5 & 65.9 & 20 \\
\hline 1995 & 702.1 & 58.5 & 53.6 & 10 \\
\hline 1996 & 789.8 & 65.8 & 109 & 20 \\
\hline 1997 & 125.9 & 104.4 & 152 & 50 \\
\hline 1998 & 1180.4 & 98.4 & 140 & 50 \\
\hline 1999 & 720.1 & 60 & 95.9 & 10 \\
\hline 2000 & 491.1 & 40.9 & 54.5 & -30 \\
\hline 2001 & 613 & 51.1 & 69 & 0 \\
\hline 2002 & 816.8 & 68.1 & 73.3 & 20 \\
\hline 2003 & 558.1 & 49 & 61.4 & -10 \\
\hline 2004 & 486.1 & 40.5 & 37.9 & -30 \\
\hline 2005 & 291.5 & 4.3 & 30.6 & -110 \\
\hline 2006 & 721.8 & 60.2 & 77.5 & 10 \\
\hline 2007 & 388.8 & 32.4 & 35.5 & -60 \\
\hline 2008 & 308.7 & 25.7 & 41.2 & -100 \\
\hline 2009 & 331.1 & 27.6 & 32.5 & -90 \\
\hline 2010 & 484.5 & 40.4 & 43.5 & -30 \\
\hline 2011 & 353.1 & 29.4 & 32.2 & -80 \\
\hline 2012 & 544.9 & 45.4 & 54.1 & -10 \\
\hline 2013 & 338.3 & 28.2 & 24 & -90 \\
\hline 2014 & 565.7 & 47.1 & 33.593 & -10 \\
\hline Totals & 15646.7 & & & \\
\hline Mean & 625.9 & & & \\
\hline Std dev & 246.213 & & & \\
\hline C.V & 0.39 & & & \\
\hline
\end{tabular}

Source. Mutisya mango farm location. Weather Station (2015)

\section{Mean $=\bar{X}=\Sigma x / n$}

Where $\Sigma \mathrm{x}=$ the summation of $\mathrm{X} \quad \mathrm{n}=$ the number of observations and $\bar{X}=$ the mean (average).

Mean for the year 1990 rainfall in Katumani $=975.9 / 12=$ 81.3 and in Kalama 856/12 $=71$.

The technique was used to compute the Mean annual rainfall e.g $500 \mathrm{~mm}-750 \mathrm{~mm}$ to indicate semi arid and below $500 \mathrm{~mm}$ to indicate arid. Kalama recorded a long term mean of 625.9 while Central Division recorded a long term mean of 736.0 over the 25 year period. The significance between rainfall variability in the two stations can be established using the students T-test to ascertain whether there was a significant difference in rainfall variability between Katumani and Mutisya. The student Ttest was employed using calculations from table 4.3 and 4.4 .

$t=\frac{736-625.9}{178.85+246.22}=\frac{110}{18.25+23.01}=\frac{110}{41.2}=2.66$
At 0.05 significant level, the result $t=2.66$ indicated a significant difference in rainfall variability between Central Division and Kalama Division. In addition, Kalama Division of Machakos sub County had more severe semi arid conditions with nine out of 25 years recording below $500 \mathrm{~mm}$ while in Central Division, most years recorded above $750 \mathrm{~mm}$ with one year (2009) recording less than $500 \mathrm{~mm}$ (Table 4.3.) and Table 4.4 on page 48 and 49 respectively shows the figures used in the calculations). $A$ related study was carried out by Ngaira's (1999). A comparison of rainfall long term total means between two Divisions in Baringo District, Marigat $(588 \mathrm{~mm})$ and Nginyang $(536 \mathrm{~mm})$ indicated severe droughts. Mburu's (2011) study compared monthly and annual totals and means of rainfall between Central Division and Mukogodo Division of the semi arid Laikipia District between 1975 2005. Findings showed that Central Division had a long term mean of $636 \mathrm{~mm}$ and Mukogodo had a long term mean of $507 \mathrm{~mm}$ implying that Mukogodo Division was drier than Central Division. This reflects similar results like those of Machakos sub County.

\section{Standard Deviation.}

It is calculated by the formulae

$S D=\frac{\sqrt{\sum(\mathrm{X}-\overline{\mathrm{X}})}}{\mathrm{N}}$

From the analysis it was observed that there were significant departures of annual rainfall totals from the mean for the 25 year period. Standard deviation technique was used to compute the extent to which annual rainfall totals deviate from the annual mean. Deviations below the Mean indicated drought years and above the Mean indicated wet years. Hence standard deviation helped to determine the drought and wet years to understand the rainfall variability patterns. The figures used in calculation of standard deviation are found on the two tables 4.3 and 4.4 Drought years in Central Division were 1995, 2004 and 2010. In Kalama Division the drought years were, 1991, 1995, 2004 and 2014. Mburu's (2011)' study results showed drought years in Central as 1999 and 2000. In Mukogodo Division of the same district the drought years were;1976,1980, Division of Laikipia District as; 1980,1982,1983,1984,1985,1987,1988,1991, $1992,1993,1994,1996,1982,1983,1985,1987,1991$ 1992,1993,1994,1995, 1996, 1999, 2000,2002 and 2005 This clearly shows that Laikipia District with more and continuous drought periods is drier than Machakos sub County. The study of Baringo District between Marigat (588mm) and Nginyang $(536 \mathrm{~mm})$ showed a more drier climate compared to Machakos sub county. The analysis of wet years and drought years assists in understanding of the variability patterns and their effect on farming activities in the study areas. Kalama with more severe drought periods recorded more crop failure. Central Division had less severe drought periods. Coffee and 
maize yields had a strong relationship with rainfall variability (drought years recording very low yields).

A similar study by Alberto (2011) in kahangara Division of Northern Tanzania, also found that cassava and potato yields had a strong relationship with rainfall variability, drought years recording very low yields. In Laikipia District, Central Division, out of 14 drought years the total number of dry months was 11 (78.6\%) for December, 12 (85.7\%) for January, 14 (100\%) for February and 11 (78.6\%) for March. In Mukogodo Division, out of 17 drought years, the total number of dry months was 12 (70.6\% for December, 16 (94.1\%) for January, 15 (88.2\%) for February and 12 (70.6\%) for march (Mburu,2011). This clearly indicates that Laikipia District is drier than Machakos sub County. The three areas are drawn from semi arid areas of Kenya, but in different parts of the country. Differences in variability is as a result of different geographical location and the physical features found in these areas. Analysis show that, Machakos sub county, Laikipia District and Marigat are semi arid areas characterized with high rainfall variability which endanger farming activities. The unpredictable nature of the onset disrupts farming calendars and programs.

\section{Drought Intensity}

Drought intensity refers is the ratio of rainfall deficit to the long term mean. (Pence et.al 2000). It is measured by the departure of rainfall from the long term mean and is expressed as a percentage. Drought intensity is calculated by subtracting the long term mean of rainfall from the annual rainfall total for a given year. For this study the long term mean (736), is the mean for the 25 years (1990 - 2014) for Central Division and a long term mean of (625) for Kalama Division. A similar study conducted in Kahangara Division in Northern Tanzania by Alberto (2013), the calculated long term Mean for 24 years 1989 2010 was (643.10). The results look almost similar though found in different climatic zones. Drought intensity is calculated as a percentage as shown below. Kalama Division was drier than Central Division. Kahangara was drier than Central Division of Machakos sub County. The differences in results could be attributed to rainfall patterns and geographical positions of the areas.

Drought Intensity $(D I)=\frac{x-\bar{X}}{x} \times 100$

Where D1 = Drought intensity.

$\mathrm{X}=$ Annual rainfall for a given year.

$\bar{X}=$ Mean rainfall for $1990-2014$ (Long term mean).

DI for Katumani (Central Division) in $1990=\frac{975.9-736}{975.9} \times$ $100=24.58$

D1 for Mutisya (Kalama Division) in $1990=\frac{856.9-625}{856.9} \times$ $100=27.06$

(Table 4.3 and Table 4.4 shows the figures used in the calculations for each year)
Doorembos (1976) suggested that a rainfall data with a DI of $0.2(20 \%)$ and a above is highly variable. This follows that Machakos sub county is highly variable.

\section{Anomaly}

Table 4.3 above shows the results of the analysis of annual rain fall anomalies in Central and Kalama Division over the 25 year historical period. Anomalies show the percentage departure of annual total rainfall from the long term mean. It is expressed as a percentage. It is calculated with the formula.

$$
\begin{aligned}
\frac{T A M-L T M}{\mathrm{TAM}} \times 100 \mathrm{~T} \quad \text { where } \mathrm{TAM} & =\text { Total annual rainfall } \\
\mathrm{TLM} & =\text { Long term mean }
\end{aligned}
$$

The rainfall anomaly has been calculated for the two weather stations, Katumani Kari in Central Division (Table 4.3) and Mutisya mango farm in Kalama Division (table 4.4). In Katumani, the highest anomalies were recorded in 2006 (+40\%), 1998 (+30\%), 1996 (-50\%) and 2009 (-50\%). 2006 and 1998 registered a positive deviation from the long term mean of $40 \%$ and $30 \%$ respectively. This indicates wet years, while 1996 and 2009 a negative of $50 \%$ from the long term mean was registered, indicating drought years. The Variations were minimal in some years such as 1993, 2001, 2013 and 2014 but very wide in 2000, 2005, 2006 and 2009. In Kalama Division, acute negative deviations from the mean were recorded such as 2008 (100\%), 2005(-110\%) and 2013 (-90\%). These were severe drought periods. The highest positive deviations were recorded in 1997 (+50\%), 1998 (50\%) and 1990 (30\%). These analysis indicate that historically there was high variability in Machakos sub County.

A similar study was conducted in Kahangara Division in Tanzania over a 21 year historical period. 8/21 years recorded a percentage above the long term mean 679.4 $\mathrm{mm}$, indicating wet years. $6 / 21$ years recorded below the mean, indicating drought years (Alberto, 2013) The study in Kahangara Division, Tanzania, revealed high anomalies both negative and positive. Exceptional dry years were 2009 and 2010 and the wetter years were1998, 2002 and 2006). The largest departures were recorded in 2009 $(99.5 \mathrm{~mm})$ and in $2002(1427.2 \mathrm{~mm})$. Normal rains may occur but the tendency has been towards below the long term mean over the 21 year period. This indicates aspects of rainfall variability in the area.

\section{Relative variability}

Relative variability refers to the sum of all deviations from the mean without respect to sign. $(-$ or +$)$ It is derived by the following formula.

R.V $=\frac{\sum(\mathrm{X}-\overline{\mathrm{X}})}{\mathrm{N} / \overline{\mathrm{X}}} \times 100$

Where $\sum(\mathrm{X}-\overline{\mathrm{X}})=$ Sum of all deviations from the mean.

33 | Int. J. of Multidisciplinary and Current research, Vol.6 (Jan/Feb 2018) 
$\mathrm{N}=$ Number of observations.

$\overline{\mathrm{X}}=$ The mean

For example the RV for 1995 Katumani Central Division = $\frac{\sum(595.5-49.6)}{12 / 49.6} \times 100=24 \%$

The RV for 1995 Mutisya in Kalama Division = $\frac{\sum(701.1-58.5)}{12 / 58.5} \times 100=32 \%$

A relative variability in the annual amounts of rainfall of less than $15 \%$ is typical in the high rainfall areas such as Atlantic and Pacific depressions. A relative variability of between $20-25 \%$ is typical of semi arid areas of the world (Doorenbos,1976). This means the reliability of rainfall is reduced very much giving way to prolonged spells of drought. Relative variability in excess of $40 \%$ is typical of deserts of Arabia, Africa, Asia and along the west coast of South America (O'Hare, 1992). The relative variability for the two stations has been calculated on annual basis as seen in table 4.3 (katumani $1990-20 \%$ and $1991-30 \%)$.

The overall long term mean for the 25 years in Central Division was 625.9 between 1990 - 2014; This analysis shows that historically, there was still some variability of rainfall either below or above the long term mean. That normal rainfall rarely occurs but the tendency has been towards below the long term mean. This confirms the aspect of rainfall variability in the sub County. This implies that farming activities are mostly affected by this variability leading to low yields. Coffee and maize yields have been heavily determined by variability patterns. High yields have been associated with low variability and low yields associated with high variability. This was also found in Laikipia District were high variability and droughts adversely affected farming activities (Mburu, 2011).

In Central Division, 11 out of 25 years recorded above normal $(736 \mathrm{~mm})$ and 13 out of 25 years recorded below normal $(736 \mathrm{~mm})$. Normal rain was recorded in one year only (2007) The wetter years were 1990, 1998, 2005 and 2012. Exceptionally dry years were 1996, 1999, 2007 and 2008. The long term mean over the 25 years was $736 \mathrm{~mm}$; Kalama Division experienced more adverse crop failure and low yields (Table 4.2). In Lakipia District both Central and Mukogodo drought intensity varied from year to year with Central recording $-52.8 \%$ with a long term mean of $636.6 \mathrm{~mm}$ while Mukogodo recorded a drought intensity of $-40.5 \%$ with a long term mean of $507.8 \mathrm{~mm}$ (Mburu, 2011). This implies that Laikipia District has a high drought intensity than Machakos Mahakos sub County. In Ethiopia, the 1984 drought recorded rainfall that was $22 \%$ below the long term mean, some areas more than $50 \%$ below the long term mean (Web et al. 1991). Similar results have been reported by Nicholson (2000) who reviewed climate variability in East Africa between 1950s to 1980 s.
The study reported high variations of rainfall totals on a declining trend. For anomalies in Kahangara Division, 7 out of 21 years had below normal rainfall $(679.4 \mathrm{~mm}), 8$ out of 21 years rainfall was above normal $(679.4 \mathrm{~mm})$ and 6 out of 21 years had normal rainfall (Alberto,2013). Kahangara had the highest anomaly in $1990(+110)$ and in 1997 (-110) compared to Machakos sub County in 1994 ($50)$ and in 2000 (-50). Kahangara had more normal rain years ( 6 out of 21years) compared to Machakos sub County where normal rainfall rarely occurs (2 out of 25 years)

\section{Coefficient of variability}

Variability is the temporal variation in rainfall from season to season and year to year. A coefficient of variability of over $20 \%$ shows that rainfall is highly variable and very unreliable. It posses uncertainty problems especially drought (O' Hare, 1992). Coefficient of variation (CV) is calculated by the following formula;

Coefficient of variability (CV) $=\sigma / u \times 100$

Where $=\sigma$ standard deviation and $u=$ mean

For example the CV for the 25 year period for Katumani (Central Division) is calculated as follows;

Coefficient of variation $(\mathrm{CV})=\sigma / \mathrm{U} \times 100=$ $178.88 / 736=0.24 \times 100=24 \%$

CV for the 25 year period for Mutisya (Kalama Division) is calculated as follows;

Coefficient of variation (CV) $=\sigma / \mathrm{U} \times 100=$ $246.22 / 625.9=0.393 \times 100=39.3 \%$

This means that Kahangara Division in Tanzania with a CV of $40 \%$ has a higher variability and unreliable rainfall as compared to Machakos sub County which is, $24 \%+$ $39.3 \%=59.3 / 2=29.65 \%$.

A CV of $24 \%$ reported in Central Division shows high variability and uncertainty in rainfall. This is an expected result as Machakos sub County is a transition zone to the dry Nyika plateau towards the Kenyan Coast (Mbula,1992). Four of the years, 1996, 2000, 2009, and $2005 \mathrm{had}$ annual totals far below the mean of $736 \mathrm{~mm}$. On the other hand a few years had rainfall totals significantly above the mean, these are 1990, 1998, 2006 and 2012. According to O'Hare (1992) a coefficient of variability of over $20 \%$ indicates a highly variable and unreliable rainfal which possess problems of uncertainty such as drought. It follows that the value of coefficient variability $0.24(24 \%)$ in the annual rainfall of Katumani station, shows that rainfall is highly variable and very unreliable in Central Division. Moreover the annual rainfall trend was also analyzed as seen in Figure 4.3 below.

Analysis show that rainfall has been slightly increasing over the twenty five years though it is insignificant $\left(r^{2}=\right.$ 0.003 ). The statistical record in figure 4.3 shows fluctuations over 25 historical year period interspersed by 
exceptionally high values in 1998 and 2006. The rather low values were experienced in 1996, 2000 and 2009.

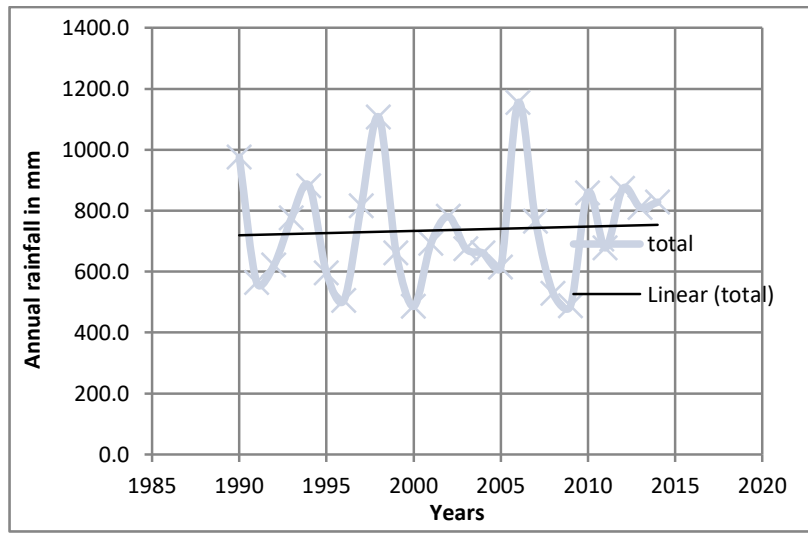

Figure 4.4 Total rainfall distribution and trends $1990-$ 2014. Katumani station

High variability is indicated by the high disparities in the study area. Alberto (2013) posits that Kahangara Division, has high variability of annual total rainfall indicated by high disparities with some years having more rainfall than others. Chances of normal rainfall are low as seen from Figure 4.1. The fluctuating patterns over the twenty five year period 1990 - 2014 (Figure 4.1) was an indication of a high rainfall variability year to year in the sub County.

Kalama Division shows a high variability and uncertainty in rainfall (CV of 39.3\%). Doorenbus (1976) suggested that rainfall data with Coefficient variability of $0.2(20 \%)$ or above is highly variable. As may be seen in 1990, 1998, 2006 and 2012 total rainfall of the years were very high compared to 1996, 2009 and 2005. The highest rainfall total recorded $1154.6 \mathrm{~mm}$ was in 2006 and the lowest recorded was $485.6 \mathrm{~mm}$ in 2000 . The overall long term mean was $736 \mathrm{~mm}$ over the last 25 years (1990 2014) for Central Division and overall long term mean of $625 \mathrm{~mm}$ over the last 25 years $(1990-2014)$ for Kalama Division. The CV for both Central and Kalama Division reveal that the two regions are classified as semi arid with varying degrees of aridity. This posses a big problem to Coffee, maize and cattle farming activities, delayed rainfall causing uncertainty on when to plant or prepare land, crop failure and low yields. In the current study the high coefficient in the two stations namely Katumani 0.24 (24\%) and Mutisya 0.39 (39\%) is an indication that the area is prone to drought which may cause desertification especially if there is mismanagement of the environment through practices such as deforestation and overgrazing. Ngongondo (2000) examined the long term rainfall variability and trends in Malawi between 1960-2000. The study found significant departures of rainfall from the annual mean of rainfall and the annual rainfall coefficient of variability (CV) for the forty years was 0.3 . A frequently used measure of rainfall variability is the coefficient of variability. According to O'Hare (1992), a coefficient of variability of less than $15 \%$ is found in equatorial regions of Zaire, Amazon and parts of Indonesia. A coefficient of over $25 \%$ is restricted in arid and semi arid regions. Areas of the world where rainfall is highly unreliable are parts of the world on dry hot desert margins where the coefficient is over 40\% (Jackson, 1997 and Parry et al., 1988). Figure 4.5 Shows total rainfall distribution and trends between 1990 - 2014. In Mutisya mango farm.

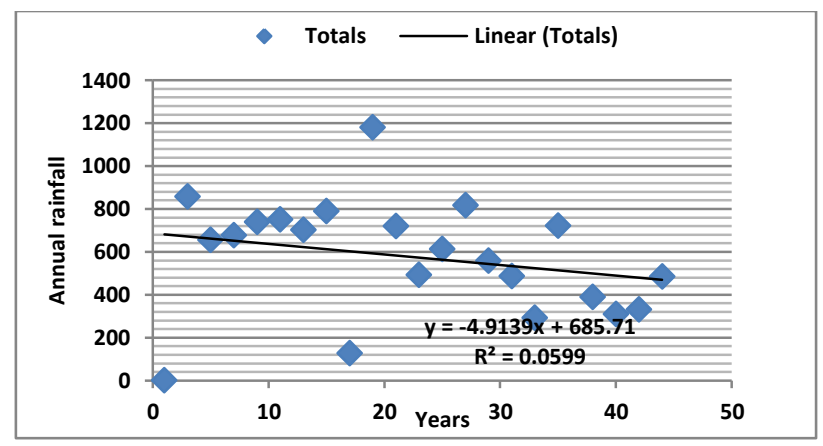

Figure 4.5 Total rainfall distribution and trends 1990 2014. Mutisya mango farm

The annual rainfall trend analyzed in figure 4.5 shows that rainfall has been decreasing over the twenty five years. The statistical record in figure 4.5 shows fluctuations over 25 historical year period interspersed by exceptionally high values in 1998, 1990 and 2002.The rather low values were experienced in 1997, 2005, 2008 and 2009. The declining rainfall is significant as $\left(r^{2}=0.059\right)$. This poses a big problem to farming activities and yields in Kalama division. Similar results have been reported by Nicholson (2000) who made a study on climate dynamics and variability in Eastern Africa between 1950 and 1980. The study found that, generally annual rainfall trend is a reduction in rainfall throughout the period.

However in anomalies, analysis showed that there were less frequent occurrences of above average rainfall throughout the continent. World meteorology organization (2000) reported that in Pampas province (Argentina) there were significant decline in rainfall between 1921 and 2000 with occurrences of extreme droughts cycle whose peak was in 1940 until 1960 (Esther 2013).

\section{Precipitation Concentration Index (PCI)}

This is an important concept in climatology which gives clues as to whether monthly rainfall is equally distributed, seasonally or highly concentrated in one month. $\mathrm{PCl}$ is calculated using the following formula; Precipitation Concentration index of two rainfall stations in Machakos sub County in Table 4.3 and 4.4, that is Central Division and Kalama Division has been calculated. Both Kalama Division and Central Division have highly, variable and erratic/unpredictable rainfall with $(\mathrm{PCl}$ of 11 and 10$)$ respectively.

35 | Int. J. of Multidisciplinary and Current research, Vol.6 (Jan/Feb 2018) 
Table 4.5 Mean monthly rainfall in mmfor the 25 year period Katumani Kari ( Central Division)

\begin{tabular}{|c|c|c|}
\hline & $\mathbf{X}$ & $\mathbf{X}^{\mathbf{2}}$ \\
\hline January & 62.0 & 3,844 \\
\hline February & 40.5 & 3844 \\
\hline March & 100.5 & $1,640.25$ \\
\hline April & 133.9 & $10,100.25$ \\
\hline May & 75.5 & $17,689.21$ \\
\hline June & 8.1 & 65.61 \\
\hline July & 3.4 & 11.56 \\
\hline August & 4.6 & 21.16 \\
\hline September & 3.2 & 10.24 \\
\hline October & 36.5 & $1,332.25$ \\
\hline November & 160.6 & $25,792.36$ \\
\hline December & 107.1 & $11,470.41$ \\
\hline & $\mathbf{\Sigma} \mathbf{X}=\mathbf{7 3 5 . 9}$ & $\mathbf{\Sigma} \mathbf{X}^{\mathbf{2}}=\mathbf{7 7 6 7 7 . 5 5}$ \\
\hline
\end{tabular}

Table 4.6 Mean monthly rainfall in $\mathrm{mm}$ for the 25 year period. Mutisya mango farm (Kalama Division)

\begin{tabular}{|c|c|c|}
\hline & $\mathrm{X}$ & $\mathrm{X}^{2}$ \\
\hline January & 70.1 & $4,914.01$ \\
\hline February & 35.0 & 1,225 \\
\hline March & 64.5 & $4,160.25$ \\
\hline April & 104.0 & 1,0816 \\
\hline May & 47.1 & 2,218 \\
\hline June & 4.9 & 24.01 \\
\hline July & 5.9 & 34.81 \\
\hline August & 3.4 & 11.56 \\
\hline September & 2.1 & 4.41 \\
\hline October & 36.4 & $1,324.96$ \\
\hline November & 152.7 & $23,317.29$ \\
\hline December & 99.5 & $9,900.25$ \\
\hline & $\sum \mathbf{X = 6 2 5 .}$ & $\Sigma \mathbf{X}^{2}=\mathbf{5 7 , 9 5 0 . 9 6}$ \\
\hline
\end{tabular}

1. $\mathrm{PCl}$ for Katumani Kari (Central division) $P C I=\frac{\sum \mathrm{X}}{\sum \mathrm{X} 2}=\frac{735.9}{77677.55} \times 100=9.8(10)$

2. $\mathrm{PCl}$ for Mutisya mango farm Center (Kalama Division) $P C I=\frac{\sum \mathrm{X}}{\sum \mathrm{X} 2}=\frac{625.6}{57950.95} \times 100=10.779$ (11) $\mathrm{PCI}=\frac{\sum \mathrm{X}}{\sum \mathrm{X} 2} \times 100$ Where $\mathrm{X}=$ the mean monthly rainfall for each month of the year.

A $\mathrm{PCl}$ value above 20 shows marked seasonal rainfall concentration. An index between $10-19$ shows erratic seasonal rainfall distribution where rainfall occurs in a few months and a value of 8 - 9 shows equal monthly distribution (Oliver, 1960). Table 4.5 and 4.6 shows the $\mathrm{PCl}$ of the two stations. These conditions create anxiety and uncertainty among the inhabitants of the region disrupting farming activities and calendars.

A similar study carried out by Ngaira (1999), found that Baringo District a semi arid region equally had erratic, unpredictable and unreliable rainfall with an average $\mathrm{PCl}$ of 11 each for the two rainfall stations. A condition that created uncertainty among the inhabitants of the region. Inhabitants become undecided whether or not to plant on the onset of sudden rainfall coming in expected dry months (season) or wait for the next wet season. They equally are not sure what to do when the rains fail suddenly during a known wet season. Analysis of annual rainfall provides significant reflection of the growing seasonal rainfall variability.

The highest $\mathrm{PCl}$ values are found in those areas where seasonal precipitation occurs in one month. Precipitation concentration index of between 8.3 and 9.0 shows equal monthly rainfall distribution. A value above 20 shows marked seasonal rainfall concentration. An index between 10 - 19 shows erratic seasonal rainfall distribution (Oliver1960). The $\mathrm{PCl}$ s of the two stations clearly indicates erratic seasonal rainfall distribution posing a risk to maize coffee and cattle farming.

Although the coefficient of variability in the two areas are different as per the shown calculations, the significance between rainfall variability in the two areas has to be established. This can be done using the students T-test as follows; In order to establish whether there was a significant difference in rainfall variability between Katumani and Mutisya the student T-test was employed using calculations from table 4.5 and 4.6.

$t=\frac{736-625.9}{178.85+246.22}=\frac{110}{18.25+23.01}=\frac{110}{41.2}=2.66$

Significant level was taken at 0.05 and the result $\mathrm{t}=2.66$ showed there was a significant difference in rainfall variability between Central Division and Kalama Division. According to Downing et.al (1989), a total annual rainfal variability of over $40 \%$ indicates that an area is prone to uncertain occurrences of drought. It is therefore difficult to predict the coming of a drought and the length of the drought in Machakos sub County. This situation brings about uncertainty in planning farming calendars and predicting the onset of rains. This interferes with crop and animal farming activities.

In the understanding of the researcher, analysis of annual rainfall provides insight and knowledge in understanding the trends in rainfall patterns and may be used to predict future patterns and trends. It may also assist in forecasting seasonal patterns and trends which is a very useful tool in planning farming activities and farming calendars. Studies such as those of Nicholson (2000), World meteorology organization (2000) and Domonkos (2003) entails regional studies of large geographical areas such as Africa, Pampas of Argentina, Malawi and Hungary. This study focused on a small geographical area; The sub County of Machakos in Kenya and how the variability affects farming activities.

\subsubsection{Analysis of Seasonal Rainfall in Central Division (Katumani Kari station)}

Maize growing seasons in Machakos sub County lies between March - June/July (MAMJJ) and between October - December/ January (ONDJ). The two seasons extent from the planting to harvesting period. The current analysis aimed at determining seasonal totals, trends and anomalies in the study area. Table 4.7 shows the monthly rainfall distribution, seasonal rainfall totals, means and 36 | Int. J. of Multidisciplinary and Current research, Vol.6 (Jan/Feb 2018) 
anomalies in Central Division of Machakos District between 1990 - 2014

Statistical analysis of seasonal rainfall for Central Division indicates that total rainfall for the entire period of 25 years (first growing Season) was $8,158.7 \mathrm{~mm}$. The long term mean was $32.635 \mathrm{~mm}$ and the Standard deviation was $13.7466 \mathrm{~mm}$. The coefficient of variation (CV) in total seasonal rainfall amounts was 0.42 (42\%) which was significantly high. The highest rainfall was recorded in 2013/2014 season (573 mm). The seasons that recorded the highest rainfall above the long term mean $(32.635 \mathrm{~mm})$ that is above $500 \mathrm{~mm}$ were $1989 / 1990$, 2011/2012, 2012/2013 and 2013/2014; The lowest rainfall was $105.3 \mathrm{~mm}$ recorded in $1992 / 1993$ season, while those seasons that recorded the lowest rainfall amount far much below the long term mean (below 200mm) were 1990/1991, 1992/1993, 1999/2000 and $2008 / 2009$. The months that received no rainfall were June, 2003 and 2005. July 1989, 2001, 2002, 2003, 2004, and 2008. August 1991, 1998, 2003 and 2008. July (mean of $3.4 \mathrm{~mm}$ ) and August (mean of $4.6 \mathrm{~mm}$ are the driest across the seasons of the historical period and Apri (mean of $69.075 \mathrm{~mm}$ ) and May (mean of $66.63 \mathrm{~mm}$ ) were the wettest in the historical period; $1990-2014$. The variability is profoundly marked in the 25 year period.

In Benin, an analysis of monthly rainfall variability between 1948 - 2002 by Yusri et.al, (2012) found that November and April were the wettest $10.9 \%$ and $11.2 \%$ of the total annual average while January and August were the driest months with $5.1 \%$ and $4.9 \%$ of the total annual average. These results are somehow similar with those of the current study as the two studies indicate April as the wettest month and August the driest. These variations in rainfall totals indicate high variability of rainfall in Machakos sub County which affects the production and yields of maize and coffee through low yields and to extremes, crop failure.

Table 4.7Monthly rainfall distribution, seasonal rainfall and anomalies 1990 -2014

\begin{tabular}{|c|c|c|c|c|c|c|c|c|c|}
\hline & Mar & Apr & May & Jun & Jul & Aug & Total (mm) & Mean & Anomalies \% \\
\hline 1989/1990 & 217 & 250.7 & 65.9 & 5.1 & 0.0 & 3.4 & 542.1 & 90.3 & 40 \\
\hline 1990/1991 & 43.5 & 80.5 & 57.5 & 3.1 & 1.4 & 8.9 & 194.9 & 32.48 & -80 \\
\hline 1991/1992 & 5.0 & 193.7 & 35.0 & 1.1 & 6.8 & 0.0 & 241.6 & 40.2 & -40 \\
\hline 1993/1994 & 70.3 & 83.6 & 29.8 & 8.2 & 3.3 & 9.9 & 208.1 & 34.68 & -60 \\
\hline $1994 / 1995$ & 150.1 & 49.6 & 33.0 & 0.9 & 4.1 & 3.2 & 240.9 & 40.15 & -40 \\
\hline $1997 / 1998$ & 118.0 & 123.0 & 162.6 & 38.7 & 15 & 2.9 & 460.2 & 76.7 & 30 \\
\hline 1998/1999 & 121.0 & 113.8 & 9.8 & 2.4 & 4.9 & 0.0 & 251.9 & 41.9 & -30 \\
\hline $1999 / 2000$ & 53.3 & 68.5 & 15.6 & 6.2 & 0.3 & 1.8 & 145.7 & 24.2 & -130 \\
\hline $2000 / 2001$ & 113 & 88.9 & 15.3 & 4.3 & 4.3 & 2.5 & 228.3 & 38.05 & -50 \\
\hline $2001 / 2002$ & 89.0 & 120.4 & 126.1 & 1.4 & 0.0 & 0.2 & 337.1 & 56.18 & 10 \\
\hline $2005 / 2006$ & 105 & 175.9 & 106.7 & 2.4 & 0.6 & 17.5 & 408.1 & 68.01 & 20 \\
\hline $2006 / 2007$ & 205 & 143.9 & 41.7 & 2.7 & 27 & 5.2 & 425.5 & 70.9 & 20 \\
\hline $2007 / 2008$ & 73 & 129.3 & 4.5 & 0.3 & 1.3 & 0.2 & 208.6 & 34.7 & -60 \\
\hline $2008 / 2009$ & 3.2 & 145.4 & 29.7 & 5.2 & 0.0 & 0.0 & 183.5 & 30.5 & -90 \\
\hline $2009 / 2010$ & 232 & 107.9 & 120.9 & 1.4 & 2.7 & 1.3 & 466.2 & 77.7 & 30 \\
\hline $2010 / 2011$ & 209.8 & 1.0 & 37.8 & 27.3 & 3.4 & 0.7 & 280 & 46.6 & -20 \\
\hline $2011 / 2012$ & 1.6 & 286.7 & 205 & 36.9 & 3.3 & 0.4 & 533.9 & 88.9 & 40 \\
\hline $2012 / 2013$ & 96.3 & 184.4 & 234.4 & 4.1 & 3.2 & 11.4 & 533.8 & 88.9 & 40 \\
\hline $2003 / 2014$ & 124.6 & 235.3 & 185.3 & 22.4 & 1.4 & 4.0 & 573 & 95.5 & 40 \\
\hline TOTALS & 2512 & 3348 & 1888 & 204 & 85 & 116 & $8,158.7$ & & \\
\hline MEAN & 100.5 & 133.9 & 75.5 & 8.1 & 3.4 & 4.6 & 32.635 & & \\
\hline
\end{tabular}

Source. Katumani Kari Centre Weather Station (2015)

The first growing season starts in March with a long term mean of $100.5 \mathrm{~mm}$ and ends in July with a long term mean of $3.4 \mathrm{~mm}$. The second maize growing season starts in October - December/January. This is the main growing season because it is wetter, with transitions of low rainfall in July long term mean (3.4 $\mathrm{mm}$ ) and September long term mean $(3.2 \mathrm{~mm})$. Variability in total rainfall amounts cuts across different months over the 25 year period during the growing seasons. For example in March 2011/2012 on the onset of the growing season the lowest rainfall was recorded. Same happened in April 2010, 2011. This delayed the planting. Coefficient of variation and standard deviation in rainfall assesses variability within the months which ranges from lowest 0.6 in March to 0.5 in April. This affects the growing crops, sometimes leading to crop failure and lowered yields. Ming-ko (1998) 
reported that most of the rainfall variability exhibit such characteristics as false onset of the rains, late onset and pronounced breaks leading to drastic alterations of expected yields.

4.4.2 Analysis of Monthly Rainfall Distribution in Machakos Sub County within the Rainy season Katumani Kari station

The historical trend of monthly rainfall totals, means, standard deviations, coefficient of variation and anomalies during the rainy seasons from 1989/1990 2013/2014 seasons is shown in Table 4.7 above.

From the Table it is clearly seen that rainfall begun in march with a long term mean of $100.5 \mathrm{~mm}$ reaching the peak in April with a long term mean of $133.9 \mathrm{~mm}$ and ended in June with a long term mean of $8.1 \mathrm{~mm}$, which is designated as a dry month. Sometimes the rains failed in March to start in April such as in the following seasons $1991 / 1992,2008 / 2009$ and 2011/2012. This is the growing season for maize and other crops. Sometimes the rains come as early as January or February such as in the seasons of 1992/1993, 1993/1994, 1997/1998, $2000 / 2001,2007 / 2008$. This is brought about by a wide variability during the said periods. This delays the planting and affects the growing of crops, sometimes leading to crop failure and lowered yields. The main planting season begins in October with a long term mean of 36.65 , reaches the peak in November With a long term mean of 160.6 and ends in January with a long term mean of 40.5

\section{March to July rainfall season}

\section{March}

In March rainfall totals above the long term mean of (100.5 mm) were recorded in the seasons of 1989/1990, $1994 / 95,1997 / 98,2000 / 2001$ and rainfall total below the long term mean were recorded in the seasons 1990/91, $1991 / 92,1993 / 94,1995 / 96,1996 / 97,1999 / 2000$, $2001 / 2002$ and $2003 / 2004$. The coefficient of variability was 0.64 (64\%) and the standard deviation was 64.29. Doorenbos (1976) posited that rainfall data with coefficient variability of $0.2(20 \%)$ or above is highly variable. There was high variability of annual total rainfall with some years having more rainfall than other years. The coefficient of variability for March is very high 0.64 (64\%). The wettest seasons were 2010/2011, $2006 / 2007$ and $1994 / 95$. The driest seasons were 1991/92, 2008/2009 and 2011/2012. The results imply that in the month of March most seasons received unreliable rainfall which was below the long term mean, implying high variability. This can adversely affect plant development leading to low yields. Similar results by Meertens et,al (1999) saw the distribution of rainfall in semi arid areas of Northwest Tanzania during the rainy season was highly variable. Distribution and length of the period of rain during the growing season is a factor that affects success of crop farming.

\section{April}

In April rainfall totals above the long term mean of $(133.9 \mathrm{~mm})$ were recorded in the seasons 1989/90, $1991 / 1992$ and rainfall totals below the long term mean were recorded in the seasons 1990/91, 1992/93, $1993 / 94,1995 / 96,1997 / 98,1998 / 1999,1999 / 2000$ $2001 / 02$, and $2003 / 2004$. The coefficient of variability was 0.52 and the standard deviation was 69.075. Since according to Doorenbos (1976) a CV of $0.2(20 \%)$ or above is highly variable, it follows that the $0.52(52 \%)$ is highly variable. The standard deviation of 69.075 indicates a very high variability for the months of April. Nicholson (2000) made similar observations in East Africa between 1950 s and 1980 s with a variability of $(50 \%)$ with a less frequent occurrence of above average annual rainfall. Another study carried out in India by Goswani et.al (2006) observed the decreasing trend and increasing variability of rainfall. The results of this study imply that in the month of April most seasons received unreliable rainfall below the long term mean; a situation affecting plant growth development leading to reduced yields and crop failure.

\section{May}

In May rainfall totals above the long term mean of $(75.5 \mathrm{~mm})$ were recorded in the seasons 1997/98, 2001/02, and 2002/2003. and rainfall totals below the long term mean were recorded in the seasons $1989 / 90$, $1990 / 91, \quad 1991 / 92, \quad 1992 / 93, \quad 1993 / 1994,1994 / 95$, 1995/1996, 1996/97, 1998/99, 1999/2000, 2000/2001 and 2003/04. The coefficient of variability was 0.9 and the standard deviation was 66.63 . Since a CV of $0.2(20 \%)$ or above is highly variable, it follows that the $0.9(90 \%)$ is highly variable. The standard deviation of 66.63 indicates a very high variability for the month of May. This was the highest recorded variability within the month. A similar study was carried out by Mos, et al., (2010), who noted the significant frequency increase of rainfall totals above the long term mean in may in East Africa. Hulme's (1996) study observed that most parts of East Africa were likely to experience $5-20 \%$ increase in rainfall from December to February by 2050 which is contrary to this study recording a sharp decline in rainfall totals which is attributed to differences in physical characteristics and human activities highly affecting farming activities.

\section{June}

In June rainfall totals above the long term mean of $(8.1 \mathrm{~mm})$ were recorded in the seasons 1997/98, 1995/96, 1997/98, 2010/11, 2011/12, 2013/14 and rainfall totals below the long term mean were recorded in the seasons 1989/90,1990/91, 1991/92, 1992/93,1994/95 1995/1996, 1998/99, 1999/2000, 2000/2001, 2001/02 and $2003 / 04$. The coefficient of variability was 1.4 and the standard deviation was 11.4. Since a CV of $0.2(20 \%)$ or above is highly variable, it follows that the $1.4(140 \%)$ is 38 | Int. J. of Multidisciplinary and Current research, Vol.6 (Jan/Feb 2018) 
highly variable. The standard deviation of 11.4 indicates a high variability for the month of June. The results imply that in the month of June most seasons received unreliable rainfall below the long term mean; Similar results were observed in Uttaranchal (USSR) by Roy, $\mathrm{S}$ and Balling, T. (2004) which found high variability in monthly rainfall. The situation adversely affects plant growth development leading to reduced yields and to extremes may lead to crop failure.

\section{July - September}

July $(3.4 \mathrm{~mm})$ and August $(4.6 \mathrm{~mm})$ and September $(3.2$ $\mathrm{mm}$ ) recoded the lowest mean rainfall across the seasons in 24 years. The second rainfall season began in October $(36.5 \mathrm{~mm})$. November $(160.6 \mathrm{~mm})$ to December $(107.1 \mathrm{~mm})$. The coefficient of variation (CV) value in the annual rainfall total obtained (Table 4.8) Shows that rainfall is highly variable and is very unreliable in the district. Since rainfall data with coefficient variability of $0.2(20 \%)$ or above is highly variable. There was high variability of annual total rainfall with some years having more rainfall than other years. The onset of the rainy season, Started in (March $100.5 \mathrm{~mm}$ ) rising to the peak in April $(1333.9 \mathrm{~mm})$ and starting to reduce in May $(75.5$ $\mathrm{mm})$ to July $(3.2 \mathrm{~mm})$, August $(4.6 \mathrm{~mm}$ and September $(3.2$ $\mathrm{mm}$ ) Which was the driest month.

In July, several years did not receive any rainfall at all. These were 1989, 2001,2002, 2003, 2004, 2008 and September 1989, 1996, 2000 and 2004. The rainfall started rising in November $(106.6 \mathrm{~mm})$, December (107 $\mathrm{mm}$ ). The Highest rainfall mean was April (133mm and CV $0.52 \mathrm{~mm}$ ) long term mean and the lowest was September (3.2mm and CV $1.5 \mathrm{~mm})$. The months of March, April, May, November and December had high monthly rainfall means over the last 24 seasons. These variations indicate high variability in Machakos sub County. The results imply that most seasons received unreliable rainfall below the long term mean; a situation affecting plant growth development leading to reduced yields and to extremes may lead to crop failure.

\section{October to December}

In October rainfall totals above the long term mean of (36.5 mm) were recorded in the seasons of $1990 / 91$, 1993/94, 1994/95,1996/97, 1999/2000, 2003/04 2008/09, 2013/2014 and 2010/2011 and rainfall total below the long term mean were recorded in the seasons 1989/90, 1991/92, 1992/93, 1995/96, 1997/98, 1998/99, $2000 / 01,2001 / 2002$ and $2003 / 2004$. The coefficient of variability was 0.8 and the standard deviation was 29.11 . Doorenbos (1976) posited that rainfall data with coefficient variability of $0.2(20 \%)$ or above is highly variable. There was high variability of annual total rainfall with some years having more rainfall than other years. The coefficient of variability for March is very high 0.64 (64\%). The wettest seasons were 1993/1994, 1994/1995.
The driest seasons were 1989/90,1995/19962, 1997/8 The results imply that in the month of October most seasons received unreliable rainfall which was above the long term mean, implying high variability. This can adversely affect plant development leading to low yields. Similar results by Meertens et al. (1995) saw the distribution of rainfall in semi arid areas of Northwest Tanzania during the rainy season was highly variable. Distribution and length of the period of rain during the growing season is a factor that affects success of crop farming.

\section{November}

In November rainfall totals above the long term mean (160.6 mm) were recorded in the seasons 1989/1990, 1993/1994, 1995/1996, 1996/1997, 1998/1999, 1999/2000, 2003/2004, 2005/2006 and 2009/2010, Rainfall totals below the long term mean were recorded in the seasons 1990/91, 1991/1992, 1992/2093, $1994 / 1995$, 1997/2098, , 2001/2002, 2002/2003 2006/2007, 2007/2008, 2009/2010, 2011/2013. The coefficient of variability was 0.52 and the standard deviation was. Since according to Doorenbos (1976) a CV of $0.2(20 \%)$ or above is highly variable, it follows that the $0.52(52 \%)$ is highly variable. The standard deviation of 69.075 indicates a very high variability for the months of April. Nicholson (2000) made similar observations in East Africa between 1950s and 1980s with a variability of (50\%) with a less frequent occurrence of above average annual rainfall. Another study carried out in India by Goswani et.al (2006) observed the decreasing trend and increasing variability of rainfall. The results of this study imply that in the month of April most seasons received unreliable rainfall below the long term mean; a situation affecting plant growth development leading to reduced yields and crop failure.

\section{December}

Rainfall totals above the long term mean of $(107.1 \mathrm{~mm})$ were recorded in the seasons 1989/90, 1990/91, $1991 / 92$, 1992/93, 1993/1994, 1996/1997,1998/1999, 2001/02, 2004/2005, 2005/2006, 20092010 and 2011/2012. and rainfall totals below the long term mean were recorded in the seasons,1994/95, 1995/1996, $1997 / 98$, 1999/2000, 2000/2001, 2002/2003 and 2006/07, 2007/2008, 2010/2011,2012/2013,2013/2014 The coefficient of variability was 0.7 and the standard deviation was 71. 974. Since a CV of $0.2(20 \%)$ or above is highly variable, it follows that the 0.7 (70\%) is highly variable. The standard deviation of 71.974 indicates a very high variability for the month of December. This was one of the highest recorded variability within the months. A similar study was carried out by Mos, et.al (2010), who noted the significant frequency increase of rainfall totals above the long term mean in May in East Africa. Hulme's (1996) study observed that most parts of East Africa were 
likely to experience $5-20 \%$ increase in rainfall from December to February by 201

\section{Summary, Conclusion and Recommendations}

\subsection{Summary of the major findings}

This study analyzed historical monthly, seasonal and annual rainfall variability of the semi arid Machakos sub County over 25 year period (1990 - 2014). The analysis identified various patterns of rainfall, in terms of distribution, frequency, trends and measures of rainfall variability using various measurement techniques such drought intensity (DI), relative variability (RV), coefficient of variability(CV) Rainfall anomalies (RA) and precipitation concentration index $(\mathrm{PCl})$ on monthly seasonal and annual scales in Machakos sub County between 1990 2014. The statistical analysis indicated that rainfall in Machakos sub County varies in each growing season within the month and annual totals. The study established that monthly rainfall distribution in Machakos sub County is extremely variable, erratic and unreliable making it difficult to plan farming activities. Variability is shown through marked differences in rainfall amounts between Central Division (Katumani station) and Kalama Division (Mutisya staion). A PCl of 10 for Kari and 11 for Mutisya, indicated erratic, unpredictable and highly variable rainfall. A high coefficient of variability Kari 0.24 (24\%) and Mutisya 0.39 (39\%) indicates erratic, unreliable and a highly variable rainfall. Kalama Division is more moisture deficient than Central Division.

\section{Conclusion}

The study assessed and analyzed the characteristics of rainfall within the study area. Temporal variability of rainfall is high at monthly, seasonal and annual scales. Total rainfall amounts were increasing and deceasing respectively. The high erratic and unreliable characteristics were established by the high PCls and CVs recorded. Variable declining trends of rainfall were also observed. The two Divisions, Kalama and Central have high variability of rainfall. These variability affects the production of maize, coffee and cattle in Machakos sub County. The variability was analyzed in terms of distribution, anomalies, trends, coefficient of variability and precipitation concentration index.

\section{Recommendations}

The meteorological department should disseminate information on rainfall forecasts to farmers so as to create awareness of the effects of rainfall variability which will help on farm decision making. Understanding of rainfall variability and patterns can assist farmers in planning and managing agricultural activities. The inhabitants of Machakos sub County should be sensitized to understand that droughts are a common occurrence and therefore pre-drought planning is important to cope up or overcome the problem. Investment in water supply where rain water is harvested and stored in reservoir tanks or dams for small scale irrigation projects to supplement rainfall.

\section{Areas of further research}

An area of further research is to analyze and establish the coping strategies of rainfall variability in Machakos sub County. Further research can be conducted on the impact of climate change on socio economic activities in Machakos sub County.

\section{References}

[1]. Alberto, K. A. (2013). Effects of rainfall variability on subsistence crop production in Kahangara Division of Magu District/ Tanzania. Unpubished Masters Thesis. Maseno University. Kenya.

[2]. Domonkos, P. (2003). Recent precipitation trends in Hungary in the contest of larger scale climatic changes. Natural Harzards. Vol.29. Pp 255- 271.

[3]. Doorenbos, J. (1976), Agrometrological field station station. FAO irrigation and drainage paper 27. FAO Rome, pp 94.

[4]. Esther, D.(2013) Copping with effects of drought. Journal of environmental science. Vol 12 Issue 60 page 26 38.GOK, (2013). Machakos County Development plan. Ministry of planning, National Development and Vision 2030. Kenya. Government printers.

[5]. Goswani, B.N., Venugopal, N., Sengupta, D., Mdhusoodam, M.S., and Xavier, P.K., (2006). Increasing Trend of Extreme Rain Events over India in a Warming(2011). Journal of environmental science 314:1442 -1445.

[6]. Gribbin, B. (1975). Agriculture in the Sahel. London; Emerald Publishers Ltd.

[7]. Hulme, J.(1996). Climate change in southern Africa. Climate R. institute, Washingtone DC.

[8]. Jesse, C Robert,(1996). Rainfall data in selected meteorological stations in Machakos District. Endinburg Uk; Cambridge University press.

[9]. Jose, N. (2007). www Tearfund. Footsteps in agriculture and climate change. V. 3.pp 21- 45.

[10].Jude, F. (2007). www Tearfund. Footsteps in agriculture and climate change. Vol 1.

[11]. Karugah, R. and Kibuuka, P. (2003). Certificate Geography. Nairobi; Oxford University Press.

[12]. Mburu,H.(2011). The effect of droughts in semi arid Laikipia District. Unpublished PhD thesis. Maseno university Kenya.

[13]. Medung, N. I., (2009). The effects climate change in Nigeria. Available at (All African com http: Allafrica.com/stones/200910010424,html) Accesed on 24/2/2014..

[14]. Minns, W. J. (1984). A geography of Africa (New Edition) Nairobi, Kenya; Macmillan Publishers.

[15]. Michael, M and Tiffen, M. (1992). Environmental change and dry land management in Machakos District 1930 - 90. Working paper 62, London. Overseas D. institute.

[16]. Mose, J. (2010). The effect of rainfall variability on farming. Nairobi, Kenya; JIT publishers.Ngaira, J. K. (1999).

40 | Int. J. of Multidisciplinary and Current research, Vol.6 (Jan/Feb 2018) 
Environmental Impact of Rainfall Variability. Unpublished PhD Thesis. Maseno University, Kenya.

[17]. Ngongondo C. S.,(2005). Analysis of longterm rainfall variability, trends and water available in Mulunguzi river catchment. Malawi journal of science and technology. Vol 7. Pp 34-44.

[18]. Nityarand, Sing, N, Ashwini Ranade.Prascad (2009). Rainfall variability in India. Weather and climate Vol.19 pp 134185.

[19]. Nicholson, T. (1989). Rainfall variability. Ibadan, Nigeria; Evans brothers.

[20]. Nicholson, S.E. (2000). The nature of Rainfall variability over Africa. Department of Meteorology, Florida State University, Tallahassee, USA.

[21]. O'Hare, N. (1992). Climate change and its effect on the environment. London; Oxford University Press.

[22]. Ojany, F. and Ogendo, R. (1973). Kenya; A study in physical and Human Geography. Nairobi Kenya; Longman Publishers.

[23]. Ovuka, M. and Suran, L.(2016). Rainfall variability in Muranga District, Kenya Geografiska Amaler series A, Physical geography Vol. 82. Pp 78-124.

[24]. Pari, L. (1988). Climate change and the environment. Newyork, USA; John Willy and sons

[25]. Philips, J.G., Rajagopalan, B., Cane, M. and Rosenzweing, C. (1999). The role of Enso in determining climate and maize yield in the US corn Belt. International journal of climatoiogy. Vol.19: Pp 877 -888.
[26]. Ribot, J. C., magalheaes, A.R and Panagides S.S.(1996). Climate variability. Climate change and social vulnerability in the semi arid Tropics. Press syndicate of university of Cambridge.

[27]. Richard, V. Rousquit (2003). Rainfall variability and changes in Southern Africa.The African Journal. Vol. 29 issue 2. Pp $139-154$.

[28].Sen Roy, S., and Balling, R. C.,(2004), Trends in Extreme Daily Precipitation indices I India. International Journal of Climatology, 24:557 -466.

[29].Shongwe, M.E.,and Oldenborgh, V., (2009). Projected changes in mean and extreme

[30]. participation in Africa and global warming. Part II: East Africa, Nairobi, Kenya. Pp 56

[31]. Tanzania Meteorological Agency (TMA), 2007. Rainfall data Dar es salaam Wenner, R. (2012).Org/Wiki/Rainfall Variability. Vol. 23. Pp 32-54.

[32]. Wesonga, P. (2011) Change in Weather/ Climate. African journal of ecology.Vol. 45:Pp53-575

[33].Young, C. and Lowry, R. (1977). East Africa. Physical and Human Geography. London Britain; Edward Arnold (publishers 